\title{
The Chromosomes of a New Haploid Oenothera
}

By D. G. Catcheside M. Sc., F.L.S.,

Asst. Lecturer, Dept. of Botany, University of London, King's College

Received May 28,1932

Parthenogenetic development of egg cells has been found in many plants and a few animals to give rise to haploid individuals simulating, in their morphological development and properties, diploid ones. The most recent summary of the literature is that of Gates and Goodwin (1930) ; they conclude that parthenogenesis may be stimulated by $(a)$ crossing, especially with distantly related species, (b) subjection to cold at the time of fertilisation, or may occur $(c)$ spontaneously, as in the tomato. They conclude also that there is good evidence for androgenesis in a few cases (see also Kuhn 1930). They point out that the occurrence of haploid sporophytes, differing from the diploid chiefly in size and reduced fertility, is incompatible with the old form of the antithetic theory of alternation of generations in plants. Moreover, the occurrence in diploids of diploid gametophytes, formed following a restitution nucleus, the result of a simple mechanical accident during meiosis, provides further evidence in the same direction. As a matter of fact, the chromosomes of the haploid set must contain mainly genes determining the various morphological and developmental processes of the sporophyte stage of the plant's lifecycle at least in higher plants.

In lower plants e.g. many Algae, the reverse is true. The somatic expression of the genic complement is seen only in the haploid phase, the diploid phase being of the simplest type. Of course it is still possible to regard the gametophytes as gametes endowed with the property of repeated asexual reproduction, organisation into thalli being a secondary phenomenon. Such a supposition however cannot be applied appropriately to Bryophytes and Pteridophytes where the gametophyte has a more or less definite and differentiated organisation, 
different from that of the sporophyte. The 'dependent' sporophyte of the Bryophytes, and of the Pteridophytes in the young stages, is perhaps a consequence of fertilisation in situ and very little more than that.

We may believe that the somatic conditions of the gametophyte in seed plants are the result of inhibition of the single set of genes in the peculiar environment of the diploid soma; the ontogenetic view discussed by Lang (1909), would seem to embody a similar idea. Normally fertilisation would destroy this inhibition and allow controlled development of the diploid sporophyte to its full expression. In haploid parthenogenesis, the inhibition is removed perhaps by abortive fertilisation (abortive in that no nuclear fusion results, the male nucleus, presumably, degenerating) or by abnormal environmental and physiological conditions. Diploid gametes would also be inhibited and consequently full sporophytic development would be prevented. The inhibition hypothesis cannot apply to lower plants where the generations are more or less independent of one another and where the two generations may be morphologically similar or different to a greater or less degree. Among the lower groups the situation is no less complicated and involves, as in the higher forms, the question of the ontogenetic relationship of genes and their apparent inhibition until a particular stage in the organism's development has been reached.

The facts indicate rather clearly that the diploid and haploid phases have little to do with the origin and significance of morphological alternation of generations. A view that appears tenable is that initially the two generations were identical in appearance and that mutations gradually brought about the divergence, the course of which was undoubtedly governed by the genetical laws controlling mixed populations. The fact that meiosis is entirely independent of the state of complexity of the chromosome complement gives it a new physiological aspect. Hedayetullah (1931) has shown that the chromosomes are essentially double throughout the nuclear cycle in root-tips; one would like to know, also, their behaviour in the division preceding meiosis and, also, in the divisions in the gametophytes. For, it is equally clear that the chromosomes at leptotene (the early prophase of meiosis) are undivided (Janssens, 1924 and others). It has been suggested (Darlington, 1931a) that pairing at zygotene is conditioned by this undivided state of the chromosomes. Essentially, chromosome division at mitosis, as distinct from separation of the daughter halves, has preceeded the inception of nuclear division; at meiosis the 
chromosomes divide after the nucleus has entered upon prophase. It then follows that meiosis-like conditions appear whenever nuclear division commences while the chromosomes are still single in nature.

Meiosis-like conditions are shown for example in maize when the recessive gene for supernumerary mitoses is present in double dose (Beadle, 1931); the supernumerary mitoses in the pollen mother cells are precisely like those figured for various haploid organisms. Meiotic conditions in a presumably haploid complement of chromosomes also provides a test of whether there are any particles common to any of the chromosomes; this should be shown up by bivalents or other chromosomal configurations resulting from chiasma formation following pairing of such similar portions. Beadle's figures 14, 15, 16, show fairly definite bivalents, which he acknowledges as "synapsis-like associations of chromosomes" but, unfortunately, regarding the chromosomes as strictly non-homologous, misses their real significance.

Haploid sporophytes (derived from acknowledged diploids, as contrasted with polyploids) have usually been regarded (tacitly) as having, in their set of chromosomes one representative of each gene, or chromosome particle, so that no pairing of the chromosomes would be possible. However, the bivalents in Beadle's maize gametophytes and the rod bivalent recorded by Emerson (1929) in haploid Oenothera franciscana controvert this belief. Davis and Kulkarni (1930) in haploid Oenothera franciscana claim that there are seven univalent chromosomes but at the same time figure and call attention to connections between some of the chromosomes which they interpret as connections persisting from a continuous spireme, supposed to exist earlier. Other haploids apparently show the same conditions, so that the phenomenon is probably general. For instance, Lindstrom and Koos (1931) are quite definite that there is absolutely no pairing in the tomato haploid $(\mathrm{n}=12)$, but their drawings show definite connections between some of the chromosomes, which they acknowledge to be "synaptic-like" conditions.

The material described in the present paper provides further evidence of definite homologous segments in fixed positions in the haploid set of chromosomes.

\section{Material and Methods}

The present haploid arose in one family of the $\mathrm{F}_{1}$ of Oe. blandina $\times$ novae-scotiae in Prof. R. R. Gates' cultures at the Royal Botanic Gardens, 
Regents Park, London in 1931. The culture consisted of two plants, one the haploid Oe. blandina (suspected on general grounds and confirmed cytologically) and the other the true hybrid (h-blandina. parviflorens). I am much indebted to Prof. R. R. Gates, F.R.S. for his permission to collect cytological material from his plants, and more particularly for his unfailing interest and helpful criticism throughout the course of the work.

Flower-buds were stripped of their sepals and plunged into Carnoy for 2 to 3 secs., washed well in water, the tops of the anthers and lower parts of the buds trimmed off with a scalpel, and the anthers then fixed in medium Flemming. The air was removed by means of an exhaust pump. Ovaries, for megaspore-mother-cell studies, were cut into short lengths, left somewhat longer in Carnoy, washed in water and fixed in medium Flemming. All material was cut at 15 microns.

The attempt to follow embryo-sac development was unsuccessful, since the material showed no stages later than early prophase in the division of the megaspore mother cell. The ontogeny of the megaspore mother cell is apparently normal ; it is originally hypodermal and becomes deep-seated by continued divisions above it.

I have much pleasure in recording my indebtedness to the Dixon Fund of the University of London for a grant for the purchase of the microscope which has been used in this study.

\section{Comparison of External Morphology of Haploid and Diploid Plants}

The table of comparative characters was drawn up using diploids grown in the same year, in the same culture bed, so that the environmental and climatic effects on the somata must have been of approximately corresponding amount in the two cases. The two types of sporophyte are contrasted below :-

Haploid
Rosette small, leaves oblong-ellip. 7
$\times 1.5 \mathrm{cms.}$ acute, nearly flat; main
vein pink; stem leaves and bracts
similar, a little smaller.

\section{Diploid}

Rosette medium size, leaves linear lanc. ellip., $15-20 \times 2.5-3.5$ crns. curly and wavy; main vein pink; stem leaves and bracts similar, but shorter and relatively broader. 
Stem reaching nearly 1 metre, weak and bending; $8 \mathrm{mms}$. diam. $5 \mathrm{cms}$. above base diminishing to $4 \mathrm{mms}$. above; a few short weak branches from middle of stem no basal ring; stem deep red, with numerous red papillae and very short hairs.

Bud cone slender, nearly cylindrical; hypanthium and sepals red, latter with narrow green stripes; abundantly hairy and with red papillae like diploid ; sepaltips short green, slightly spreading.

Petals $24 \times 20 \mathrm{mms}$; commenced flowering July 12; style apparently abnormally long (actually the hypanthium is relatively shortened and the style projects further); anthers small, empty-looking; inflorescence very lax.

Capsules very small, slender, with very few seeds.
Stem reaching 1.5 metres, stout, erect; $10-12 \mathrm{mms}$. diam. $5 \mathrm{cms}$. above base, diminishing to $6 \mathrm{mms}$. above; a ring of basal branches, very few above; stem diffusely red, with numerous red papillae and short patent hairs.

Bud cone stout, conical, tapering; hypanthium and sepals red-tinged, with narrow green stripes; sepal-tips of medium length green, a little spreading.

Petals 40-44 × 48-52 mms.; commenced flowering July 25; style $1 \mathrm{~cm}$. above ring of anthers; anthers large, plump; inflorescence lax.

Capsules large; reaching 30-35 mms., stout; full of seeds.

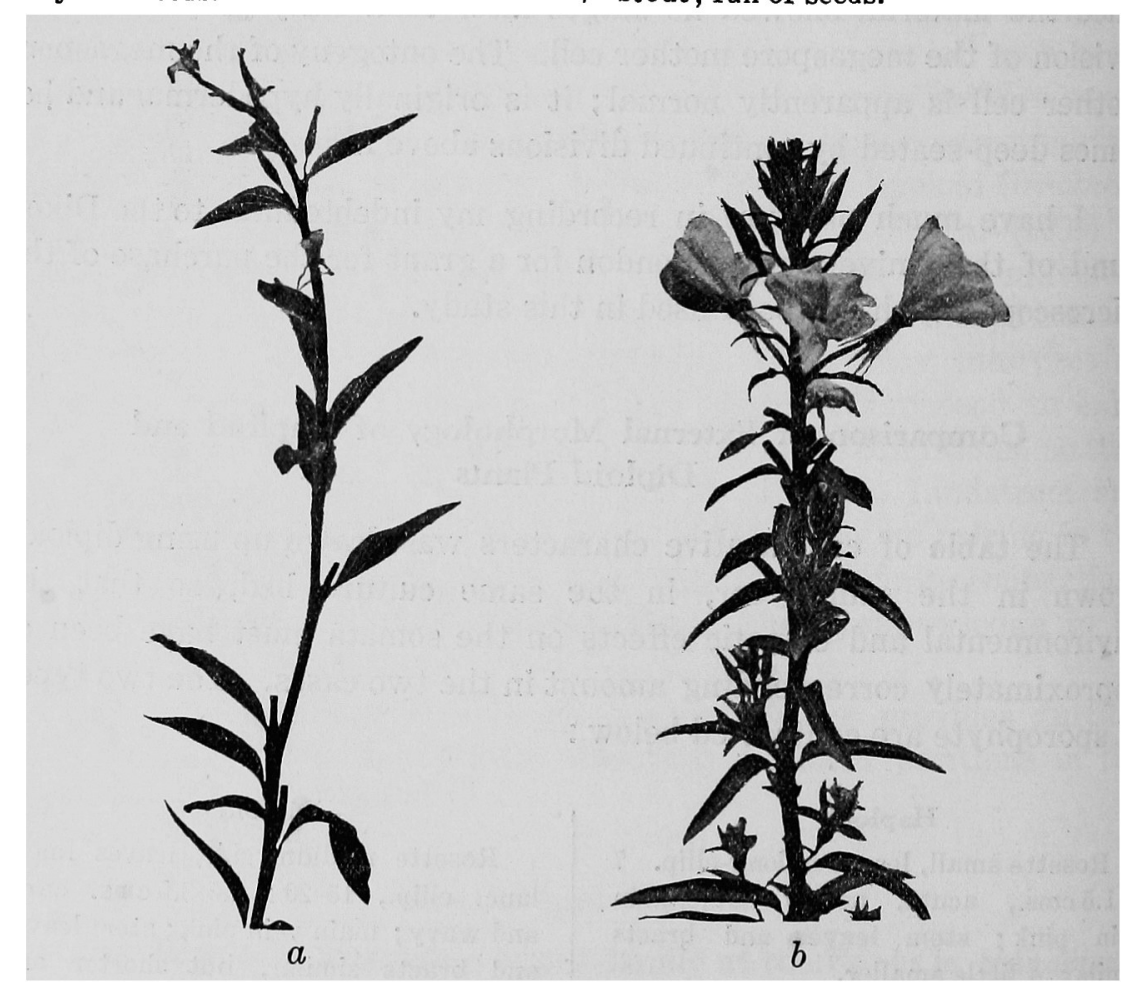

Text-fig. 1. Oe. blandina inflorescence $(a)$ of haploid, $(b)$ of diploid. 
The differences it is clear are all to be related to the smaller size of the haploid and its very low production of viable gametes and consequently reduced seed fertility. Text-fig. $1 \alpha$ is of the diploid and Textfig. $1 b$ of the haploid at about the same reduction and the two show well the comparative vigour of the plants. Text-fig. 2 shows the details of a single flower of the haploid; the particular spike shown has a number of small abortive flower buds below the open flower. The long style carrying the stigmas well above the small, slender anthers, obviously renders selfpollination an impossibility.

\section{Seed Fertility}

The nature of the haploid plant was not settled till after the breeding season. Four attempts at selfpollination failed completely, the capsules neither developing in size nor producing even a few seeds; they gradually shrivelled and finally fell off. Twenty open-pollinated

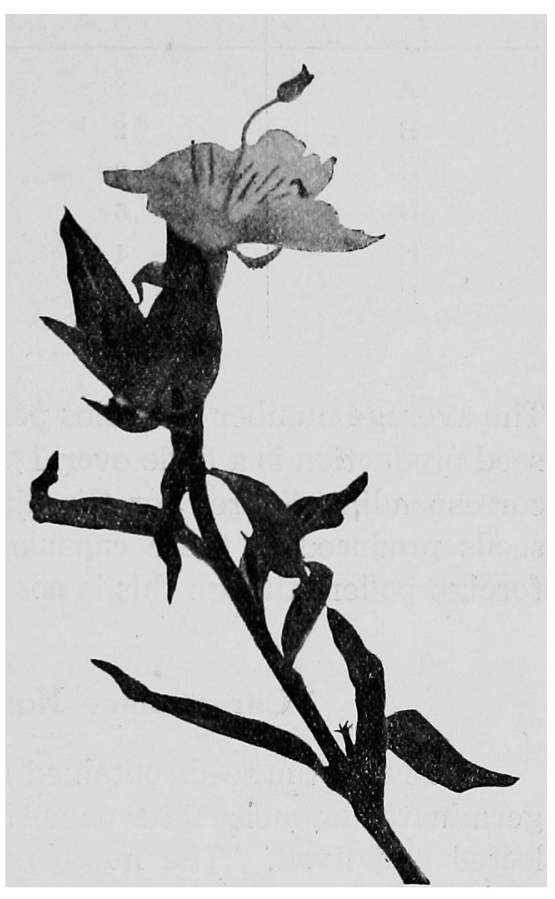

Text-fig. 2. Oe. blandina haploid, details of a single flower. capsules, collected in November, yielded 73 seeds, an average of 3.65 seeds per capsule. The majority of these were relatively small, but there were a few larger well formed ones. They were distributed amongst the capsules as shown in Table 1.

Table 1

\begin{tabular}{l|lllllllllll}
\hline No. of seeds per capsule & 0 & 1 & 2 & 3 & 4 & 5 & 6 & 7 & 8 \\
\hline No. of capsules & 2 & 2 & 3 & 2 & 5 & 1 & 3 & 0 & 2
\end{tabular}

In the case of six capsules, the number of undeveloped ovules was also determined as accurately as possible; the results are in Table 2. 
Table 2

\begin{tabular}{c|c|c|c}
\hline Capsule & No. of seeds & $\begin{array}{c}\text { No. of undeveloped } \\
\text { seeds }\end{array}$ & Total \\
\hline A & 3 & 287 & 290 \\
B & 2 & 319 & 321 \\
C & 3 & 306 & 309 \\
D & 5 & 301 & 306 \\
E & 4 & 294 & 298 \\
F & 1 & 322 & 328
\end{tabular}

The average number of ovules per capsule is therefore 308 , so that the seed production is a little over $1 \%$ of that theoretically possible. The corresponding figures for the diploid are not available. Probably the seeds produced in these capsules are the result of fertilisation with foreign pollen, though this is not necessarily the case.

\section{Chromosome Numbers in the Progeny}

A few of the seeds obtained from the open pollinated capsules were germinated on moist filter paper in a petri dish, and the root tips collected and fixed. The numbers of chromosomes found in the roots showed that 5 of the embryos were diploid, with 14 chromosomes, while one was haploid, with 7 chromosomes. The remainder of the seeds will be grown on this year, and it is hoped that the haploid can be recovered from these. Other workers e. g. Davis \& Kulkarni (1929), have obtained haploids as well as diploids and other mutant types, from haploid sporophytes.

\section{Pollen Grains}

The pollen grains are mostly small ill-formed and often wrinkled and shrunken in appearance and are usually devoid of contents. They are mostly 2 - or 3 - lobed, occasionally 4 - lobed. There are also occasional grains (mostly 3-lobed, a few 4-lobed) normally filled with contents, including starch grains. The principal types are illustrated in Textfig. 3. The grain shown at Text-fig. $3 d$ is a multiple one, formed by non-separation of sister diad cells. The observations are in agreement with those of the other workers (cf. Davis \& Kulkarni, 1930). 

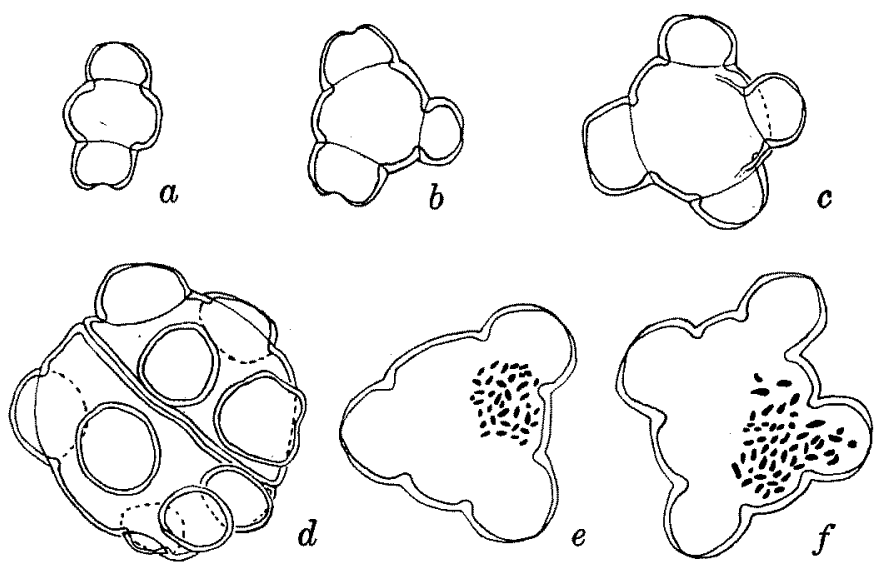

Text-fig. 3. Oe. blandina haploid, pollen grains; $(a-d)$ empty; $(e, f)$ good ; $(d)$ shows a peculiar multiple grain, due to non-separation of sister diads.

\section{Chromosome Numbers and Morphology}

In Text-fig. $4 a$ is shown the metaphase somatic complement from a root tip of the diploid, which may be compared with Text-figs. $4 b$ \& $4 c$ showing respectively late prophase and metaphase in an anther wall and petal. The chromosomes in the somatic tissue of the haploid are less well fixed and more shrunken than those of the diploid, probably because they have been affected by the Carnoy's fluid used to remove wax from the anthers and to kill the wall tissues rapidly. The correspondence of the chromosome types is, however, clear. All seven chromosomes of the haploid set have nearly median attachment constrictions;

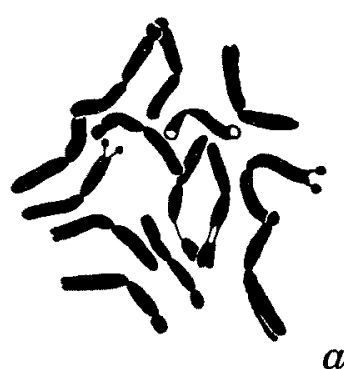

$a$

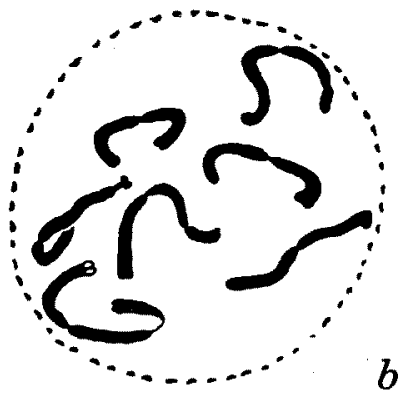

$b$

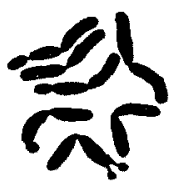

$c$

Text-fig. 4. Oe. blandina'somatic"chromosomes; $(a)_{\star}$ diploid polar metaphase plate; $(b)$ haploid chromosomes from late prophase nucleus somewhat spread out, from anther wall cell ; (c) haploid polar metaphase plate, from_petal cell. $\times 4,200$. 
one has a trabant, two have a subterminal supernumerary constriction and a fourth has an interstitial constriction, often with a remarkably long connection. The lengths of the somatic chromosomes are from 2.8-3.6 $\mu$; those in the somatic plates of the haploid often appear rather shorter, probably owing to shrinkage caused by the Carnoy's fluid.

\section{Pollen Mother-Cell Development}

The general and detailed morphological features of diploid $O e$. blandina are repeated in the haploid even down to the binucleate tapetum well stocked with food material. A slight but characteristic difference is to be noted in the more prolonged adherence of pollen mother-cells to one another, long after they are separated from the tapetal cells. This non-separation can be traced later than the tetrad stage; in diploid material, the mother-cells are separated by metaphase I.

The progression of stages is usually from the ends of anther towards the center, the top most often being furthest advanced. This succession, however, is always interrupted by the presence of transverse plates of sterile tissue in the loculi, a feature characteristic of Oenotheran anthers. The pollen mother-cells in different segments of a loculus are often at markedly different stages of meiosis. There is, therefore, a close correlation between mother-cells in any one segment, but only a loose general parallelism between those of different segments, loculi and anthers, the difference becoming greater with the greater physiological isolations.

The early prophase stages of meiosis appear much like those in the diploid, complete analysis of the seven much coiled leptotene and pachytene chromosomes being an impossible task. The nuclear contents are more or less strongly polarised at a stage corresponding to synizesis in the diploid. The significance of this phenomenon at this stage will be discussed later. At zygotene it is possible in favourable nuclei to trace certain of the chromosomes as looped threads their free ends being grouped more or less at one side of the nuclear cavity (Textfig. $5 a$ ).

The doubleness of the pachytene thread usually can be seen especially at a somewhat late stage. Whether these double portions always represent sister chromatids is somewhat uncertain; possibly some of the double threads seen in the tangle are actually paired segments of two chromosomes. The difficulty lies in the fact that no one thread 
can be followed far in the close tangle, a contraction stage to which the term synizesis has frequently been applied. Quite often, too, some of the threads in the mass appear to be single, suggesting that the doubleness of the chromosome does not arise simultaneously throughout its length.
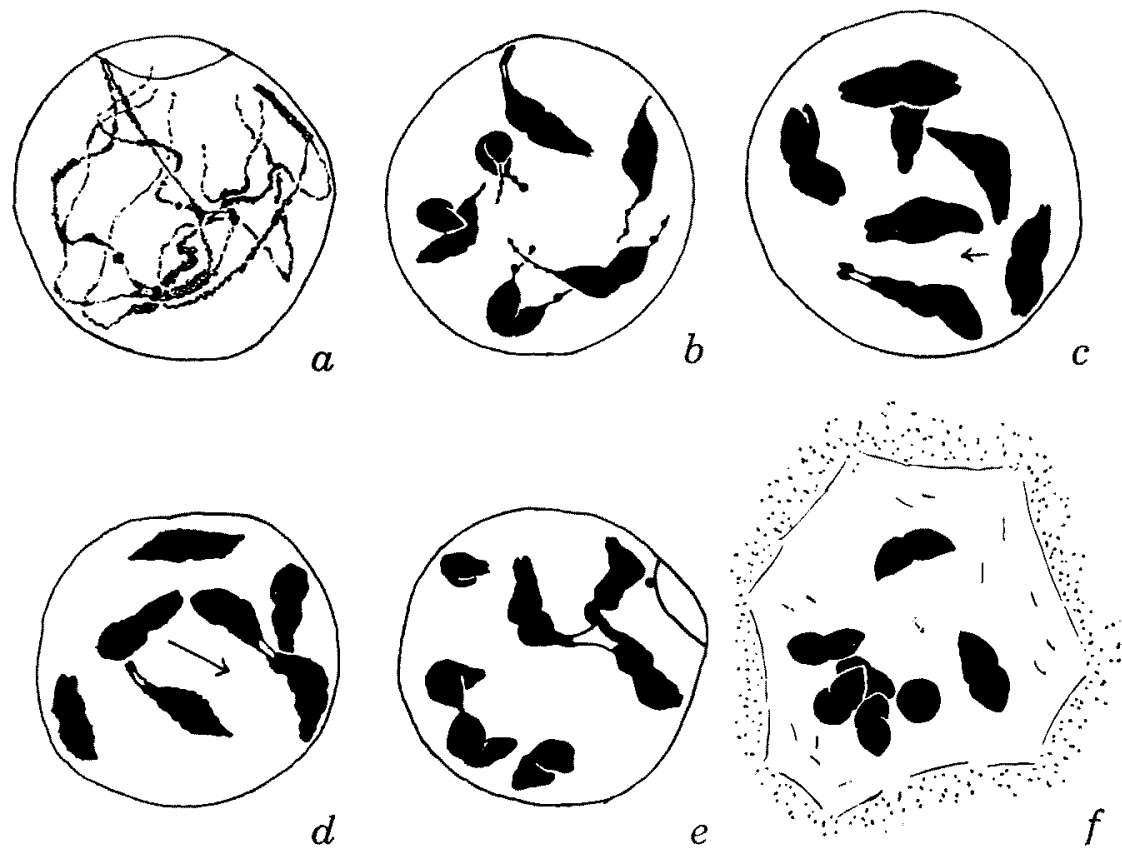

Text-fig. 5. Oe. blandina haploid meiosis; (a) zygotene showing four chromosomes somewhat polarised and paired over short lengths; $(b)$ early diakinesis with 7 (I); (c) diakinesis with 7 univalents; $(d)$ diakinesis with 1 bivalent +5 univalents; $(e)$ diakinesis with 1 trivalent +1 bivalent +2 univalents ; $(f)$ multipolar spindle stage (prometaphase) with 7 univalents. $\times 4,200$.

Pachytene is very prolonged but the actual contraction to the diakinesis chromosome proceeds rapidly when once started. The contraction, further, begins at the centre of the chromosome-perhaps at the attachment constriction-and extends distally. Stages before condensation is complete show a swollen central portion very gradually tailing out into longer or shorter uncondensed granular threads at the two ends (Text-fig. $5 \mathrm{~b}$ ): the attachment constriction is always well marked.

The successive stages distinctly suggest that the movement of the chromosome particles begins at the centre at the attachment constric- 
tion, and not from the ends inwards, or uniformly throughout the whole length. It is as though the attachment constriction was revolving about the long axis of the chromosome, coiling up the chromonema either side of it. At a stage previous to diakinesis, and corresponding to late diplotene and the second contraction of many authors, the chromosomes are more or less collapsed into a ball, a feature which will be considered later on.

Diakinesis most frequently shows the seven chromosomes entirely free from one another, but rarely a bivalent or other association type may be seen. Exact observation is difficult at diakinesis compared with metaphase I, since at the latter stage the regular relationship of the chromosomes to the spindle provides a valuable guide to the orientation and association of the chromosomes relative to one another. The actual numbers of nuclei observed at diakinesis are 54 with 7 univalents (Text-fig. $5 \mathrm{c}$ ), 4 with a rod bivalent and 5 univalents (Textfig. $5 d$ ), and 1 with a Y-trivalent, a rod bivalent and two univalents (Text-fig. $5 e$ ). Compared with the metaphase observations (vide infra), there is an excess of nuclei with univalents only; the figures probably cannot be taken as even an approximation to the proportions of the various types. However, the observations serve to demonstrate the occurrence of bivalents and multivalents at a stage prior to metaphase I. The chromosomes, in favourable cases, can be seen clearly to have double ends, that is they are longitudinally split apparently like mitotic chromosomes, except that they are much more contracted (Text-fig. $5 b-c)$. That there must be another difference will appear later. A normal multipolar spindle stage (Text-fig. $5 f$ ) intervenes between diakinesis and metaphase I.

The size of the nucleus is an approximate function of the number of chromosomes contained within it when the size of the chromosomes is a fixed quantity. At diakinesis, the average diameter of the pollen mother-cells is $8.75 \mu$, while in the diploid, fixed in a similar manner, the average diameter at the same stage is $12 \mu$. In haploid and diploid the ratio of the diameter is therefore $1: 1.37$, the ratio of the surface areas of the nuclei $1: 1.88$, and the ratio of their volumes $1: 3.52$. Possibly, the nuclear area is of greater significance than the nuclear volume, since the chromosomes are peripheral in position in the resting nuclei. The surface of exchange between nucleus and cytoplasm would appear to be of more importance to the chromosomes than the actual spherical volume occupied by them together with the karyolymph. We may reasonably conclude, therefore, with Boveri (1905) that the 
nuclear area is a function of chromosome number, other things being equal. The figures for Oe. Lamarckiana and the tetraploid Oe. gigas, however, indicate a closer agreement with a volume relationship (cf. data given by Gates and Goodwin, 1930).

At the earliest stage of metaphase I observed, the univalent chromosomes are arranged with their long axes more or less in the axis of the spindle and their spindle attachment constrictions nearly in one plane, that of the equator of the spindle. Multivalent associations of chromosomes have been seen at metaphase in a significantly large number of cases; they are of definite types which can be clearly recognised time after time. The actual configurations observed are mostly rod bivalents, and $\mathrm{Y}$ - or $\mathrm{V}$ - shaped trivalents involving terminal, subterminal, interstitial and termino-interstitial ${ }^{1)}$ chiasmata. The actual combinations of association types and the numbers observed are recorded in Table 3.

In analysing the chromosome associations, the following standpoints have been adopted:-

(1) That any pairing between the chromosomes is conditioned by individual attraction of like particles (or genes); unlike particles (or genes) do not pair. Hence, allelomorphic genes do not pair, since they are unlike, but are brought close together owing to the homologies of the neighbouring genes. The pairs of chromosomes are therefore never strictly homologous, except in a completely homozygous organism.

(2) That pairing occurs at zygotene between any homologous parts of the chromosomes, no matter how short they may be. In an extreme case but a single gene may be involved in the short homologous lengths. Pairing occurs when the chromosomes, are still single in nature, i.e. before they are split longitudinally.

(3) Chiasmata, as a result of cytological crossing-over (see discussion), occur at random in the paired portions when the chromosomes split. Association of the chromosomes subsequent to the longitudinal split is maintained only by chiasmata, and further such chiasmata only appear in segments previously paired. Paired portions in which no chiasmata have appeared tend to drift apart after the chromosomes have split, so that the evidence of previous pairing is lost. The type of association before and after the splitting of the chromosomes is therefore different in principle;

1) The term lateralchiasma used by Darlington (1931 a) is a simpler description. 
Table 3

Chromosome configurations at metaphase I in haploid Oenothera blandina.

\begin{tabular}{|c|c|c|c|c|c|}
\hline \multirow{3}{*}{ Chromosomal configuration } & \multicolumn{5}{|c|}{ No. of cases } \\
\hline & \multicolumn{4}{|c|}{ Slides no. } & \multirow{2}{*}{ Total } \\
\hline & 7 & 16 & 17 & 18 & \\
\hline $7(1)$ & 14 & 299 & 512 & 113 & 938 \\
\hline $1 \operatorname{rod}(2), X a$. term. $+5(1)$ & 4 & 29 & 79 & 11 & 123 \\
\hline $1 \operatorname{rod}(2)$, Xa. subterm. $+5(1)$ & & 11 & 36 & 9 & 56 \\
\hline $1 \operatorname{rod}(2)$, Xa. int. $+5(1)$ & & 2 & 11 & 2 & 16 \\
\hline $1 \operatorname{rod}(2)$, Xa. term.-int. $+5(1)$ & 1 & 4 & 17 & 2 & 23 \\
\hline 1 ring (2), Xta. term. subterm. $+5(1)$ & & & 1 & & 1 \\
\hline $1 Y(3), 2$ Xta. term. + $4(1)$ & & 2 & 3 & & 5 \\
\hline $1 \mathrm{~V}(3), \mathrm{Xta}$. term. \& term.-int. $+4(1)$ & & 1 & 3 & & 4 \\
\hline $1 \mathrm{~V}(3)$, Xta. subterm. \& term.-int. + (4) (1) & & & 1 & & 1 \\
\hline $1 \mathrm{~V}(3), \mathrm{Xta}$. term. \& int. $+4(1)$ & & & 1 & & 1 \\
\hline $2 \operatorname{rod}(2), X$ ta. term $+3(1)$ & & & 1 & & 1 \\
\hline $\begin{array}{l}1 \text { rod (2), Xa. term. }+1 \text { rod (2), Xa. } \\
\text { subterm. }+3(1)\end{array}$ & & 2 & 3 & 1 & 6 \\
\hline $\begin{array}{l}1 \text { rod (2), Xa. term. }+1 \text { rod (2), Xa. } \\
\text { int. }+3(1)\end{array}$ & & & 1 & & 1 \\
\hline $\begin{array}{l}1 \text { rod (2), Xa. term. } \\
\text { term.-int. }+3(1)\end{array}$ & & & 2 & & 2 \\
\hline $\begin{array}{l}1 \text { rod (2), Xa. subterm. + } 1 \text { rod (2), } \\
\text { Xa. int. }+3(1)\end{array}$ & & & 1 & & 1 \\
\hline $\begin{array}{l}1 \text { rod (2), Xa. subterm. }+1 \text { rod (2), } \\
\quad \text { Xa. term.-int. }+3(1)\end{array}$ & & 1 & 4 & & 5 \\
\hline $\begin{array}{l}1 \text { rod (2), Xa. int. }+1 \text { rod (2), Xa. } \\
\text { term.-int. }+3(1)\end{array}$ & & & 1 & & 1 \\
\hline $1 Y(3)+\operatorname{rod}(2), X a$. term.-int. $+2(1)$ & & 1 & & & 1 \\
\hline $1(4)+3(1)$ & & & 1 & & $\frac{1}{1186}$ \\
\hline
\end{tabular}

Explanation of abbreviations used :- $(1)=$ univalent ; $(2)=$ bivalent ; $(3)=$ trivalent ; $(4)=$ quadrivalent; Xa. = chiasma ; Xta. = chiasmata ; term. = terminal ; subterm. = subterminal ; int. = interstitial; term,-int, = termino-interstitial. 
before the split, association is conditioned by the pairing of the individual homologous particles concerned; after the split, association is conditioned by a chiasma, in which a particular chromatid is paired with different chromatids either side of the chiasma.

(4) Each chiasma is terminalised, that is it moves away from the attachment constriction towards the end of the chromosome limb in which it occurs. This movement goes on until the distal end of the homologous segment is reached, for pairing of the chromatids subsequent to chiasma formation (i.e. at diplotene) is conditioned by the same principles that govern pairing of the leptotene chromosomes at zygotene (vide (1) supra). Hence, chromatid particles can pair only if they are homologous; if non-homologous or allelomorphic (allelomorphs are really dissimilar genes occupying the same relative positions in the chromosomes) they will not pair, but may be brought together by the attraction of pairs of neighbouring genes that are similar. When at the distal end of paired homologous segments, the chromosomes become different in their homologies over a considerable distance, (more than a few genes), a chiasma terminalising in the homologous region will be prevented from moving beyond the end of this segment. In the haploid, then, the positions of the chiasmata at metaphase I mark the distal ends of the homologous segments.

Bearing these points in mind, it will be seen that the different chiasma types mentioned above (terminal, subterminal, interstitial and termino-interstitial) are the result of pairing in four different, probably unrelated, segments, each present in at least two of the seven chromosomes. It is by no means certain that the same segments are always involved in a given metaphase configuration; in fact, there is evidence, though not completely decisive, that there are more than the four different segments mentioned above. The segments will be considered individually in respect of the positions in the chromosomes occupied by them, and an attempt will be made to relate the segments to one another and to the different chromosomes. For the sake of convenience, the fourteen limbs of the seven chromosomes may be labelled as follows :-
A.B
C.D E.F
G.H
K.L M.N
O.P

while the segments under survey may be designated as follows :-

$\mathbf{t}=$ segment giving terminal chiasma

$\mathbf{s}=$ segment giving subterminal chiasma 


$$
\begin{aligned}
& \mathbf{i}=\text { segment giving interstitial chiasma } \\
& \mathbf{u}=\text { segment giving termino-interstitial chiasma (as in } \\
& \text { "unequal " bivalent) }
\end{aligned}
$$

Seven univalents at metaphase I are shown at Text-fig. $6 a$ and Pl. 1, Fig. 1.

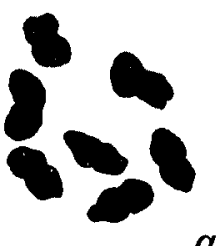

$a$

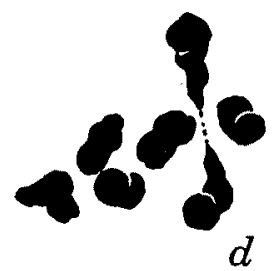

$d$

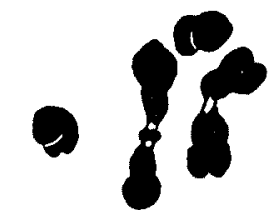

$g$

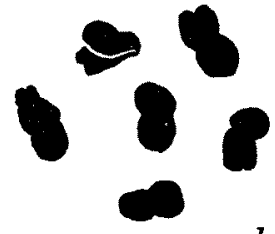

$b$
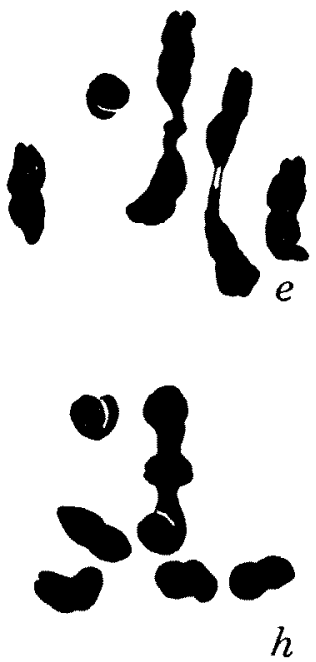

$h$

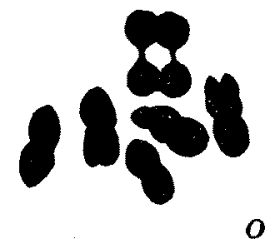

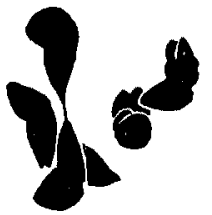

C
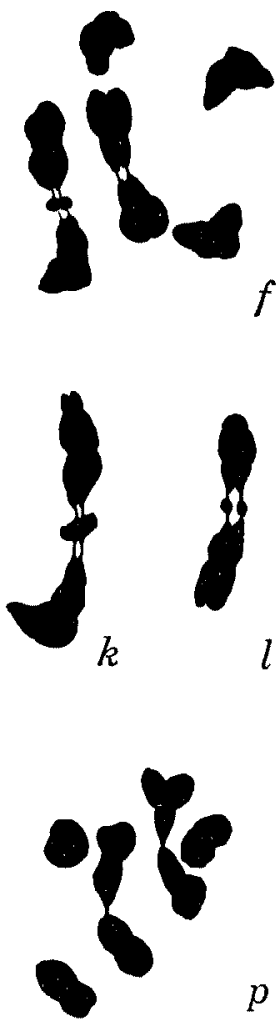

Text-fig. 6. Oe. blandina haploid meiosis metaphase I; $(a)$ \& (b) polar view, remainder profile; (a) 7 univalents; (b) 1 bivalent +5 univalents; (c) \& $(d) 1$ bivalent +5 univalents; $(e)-(g)$ \& $(p) 2$ bivalents +3 univalents; $(h) 1$ bivalent, with interstitial chiasma, +5 univalents; $(k),(l),(n)$ rod bivalents with subterminal chiasmata ; $(m)$ univalent with apparent trabant; $(0)$ anomalous association of 2 chromosomes. $\times 4,200$. Full description in text. 
(1) Segment giving terminal chiasma. The segment $t$ is apparently relatively long compared with the other segments, giving out of 1186 metaphases examined 123 with a rod bivalent and 5 univalents (Text-fig. $6 b, c, d$, Pl. 1, Figs. 2, 3, 5, 10), 2 with 2 rod bivalents and 3 univalents (Text-fig. $6 p$, Pl. 1, Figs. 4-6) 1 with a ring bivalent (Textfig. $7 g$ and Pl. 1, Fig. 7), in which one of the chiasmata is terminal, and 9 others with a rod bivalent occurring with some other association type. In addition, there are a number of other chromosomal associations involving in all 17 terminal chiasmata. Hence, there is a total of 154 terminal chiasmata in the metaphases examined; but there are probably more than two representatives of the segment $t$ as shown below. In the case of metaphases where two bivalents have been observed, one of them is often the result of the operation of the terminal segment, giving a terminally associated rod bivalent. This may occur together with another terminally associated rod bivalent (Text-fig. $6 p$ ), with a subterminally associated rod bivalent (Text-figs. $6 e, f, g$,), with an interstitially associated rod bivalent (Text-fig. $7 r$ ) or with an unequal rod bivalent associated termino-interstitially (Textfig. $7 \mathrm{~g}$ ). Two terminal chiasmata make up the triple union seen in the Y-trivalent (Text-fig. $7 o$ and Pl. 1, Fig. 8). The terminal segment occurs in two of the $\mathrm{V}$-shaped trivalent type; in one the second chiasma is termino-interstitial (Text-fig. $7 h, k$ ), in the other it is interstitial (Text-fig. $7 \mathrm{~m}$ ). It occurs also in the ring bivalent (Text-fig. $7 \mathrm{q}$ ) in which the other chiasma is subterminal. Finally, in the quadrivalent (Text-fig. $7 p$ ), three of the chromosomes are associated in a triple union involving a terminal and a subterminal chiasma; also one of the chromosomes with the subterminal chiasma is associated terminally at its other end with a fourth chromosome.

In no case has a chromosome been found with its two ends joined, for instance by a terminal chiasma, so that there is every probability that the two ends of each chromosome are different in their pairing properties. The terminal segment, however, occurs in at least three of the chromosomes (shown by the Y-trivalent with two terminal chiasmata) and these may be labelled tA.B, tC.D and tE.F respectively, There are certain indications that there is a second terminal segment $\mathbf{t}^{\prime}$ common to two of the chromosomes; the case of two terminally associated bivalents in the same cell may be interpreted in this manner, or may be supposed to show that a fourth chromosome also possesses the same terminal segment $t$. The latter possibility is unlikely in view of the infrequency of cells with the two rod bivalents (two cases), 

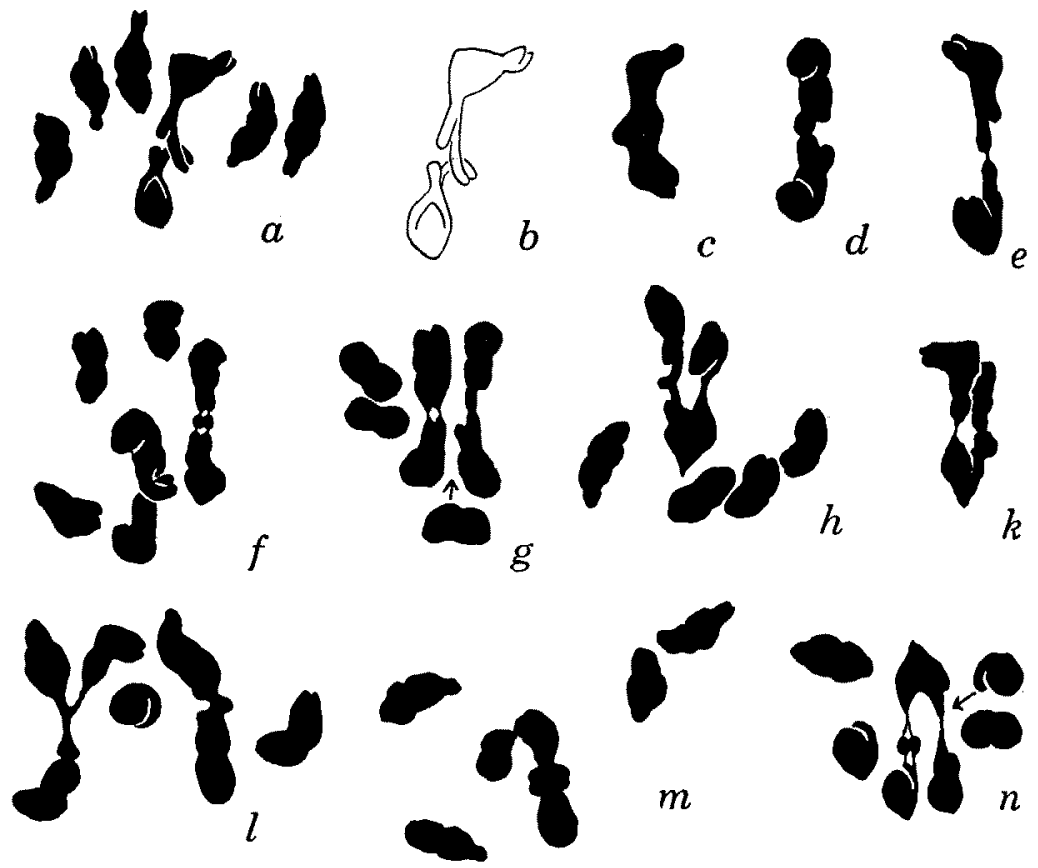

$m$
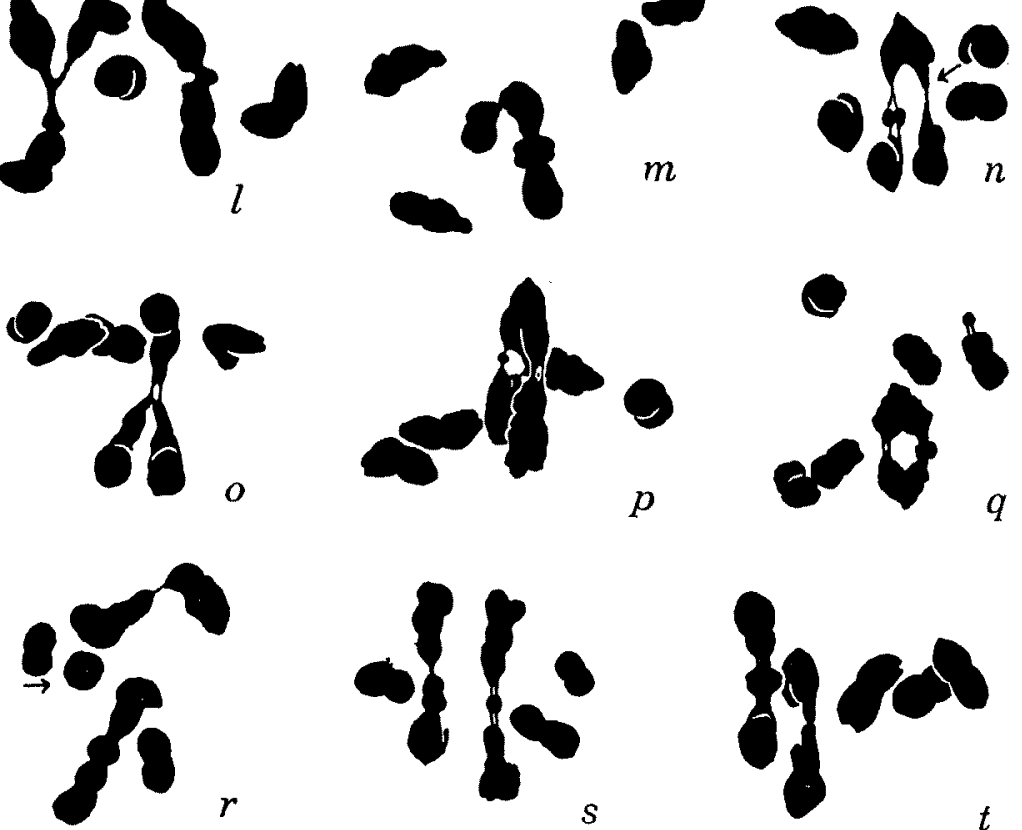

Text-fig. 7. Oe. blandina haploid meiosis, metaphase I, profile views; $(a)-(e)$ unequal bivalent; $(f),(g),(r)-(t) 2$ bivalents +3 univalents ; $(h),(k),(n)$ V-trivalent, involvng unequal chiasma; $(l) 1$ Y-trivalent +1 unequal bivalent +2 univalents ; $(m) 1$ V-trivalent, involving interstitial chiasma; (o) V-trivalent +4 univalents; $(p)$ branched chain quadrivalent +3 univalents; $(q)$ ring bivalent +5 univalents. $\times 4,200$. Full descriptions in the text. 
compared with the frequency of the terminal association (154 in 1186 cells). One of the chromosomes, bearing the segment $t$, carries in its other limb the segment $\mathbf{u}$ giving the termino-interstitial association (cf. Text-figs. $7 h, k$ and Pl. 1, Fig. 11) and may be labelled tA.Bu without indicating whether the segment $\mathbf{u}$ is in the terminal or the interstitial position (vide infra). The ring bivalent (Text-fig. $7 q ;$ Pl. 1, fig. 7) shows that two of the chromosomes carrying the segment $t$ also carry the segment s (subterminal), in each case in the opposite limb. Which two of the chromosomes are involved is quite uncertain. If the $\mathbf{u}$ segment in tA.Bu is interstitial, it is possible that $\mathbf{u}$ is identical with the s segment of the ring bivalent, but the V-trivalent, shown at Text-fig. $7 n$ and Pl. 1, Fig. 12 demonstrates that the s segment is distinct from the interstitially placed $\mathbf{u}$ segment. Finally, the terminally placed $\mathbf{u}$ segment may be identical with one of the duplicated or triplicated $\mathbf{t}$ segments.

(2) Segment giving subterminal chiasma. Judging from its lower frequency, segment $s$ is probably somewhat shorter than segment $t$, but due allowance must be made for the fact that $t$ is represented at least three times while $s$ is probably present in duplicate only. It has already been shown that segment $\mathbf{s}$ is probably distinct from the interstitially placed representative of the pair of $\mathbf{u}$ segments. It is very likely, however, that there is a second segment giving a subterminal chiasma (=segment $\mathbf{s}^{\prime}$ ), since the size of the distal arms may be very small (Text-figs. $6 e, f, g, l, n ; 7 n, p$ Pl. 1, Fig. 3 ) or relatively larger (Text-figs. $6 k ; 7 b, q$ ). The smaller limbed type (from segment s) is much the commoner, but it is impossible to classify the bivalents accurately in every case. It is likely, however, that segment s accounts for more than $80 \%$ of the subterminal associations, while segment $s^{\prime}$ is responsible for the remainder. It seems certain also that another segment must be segregated off from $s$ as $s^{\prime \prime}$ since (Text-fig. $7 n$ and Pl. 1, Fig. 12) shows that one of the chromosomes containing $\mathbf{u}$ contains a subterminal segment $\left(\mathrm{s}^{\prime \prime}\right)$ in its other limb, whereas Text-fig. $7 f$ shows that segment $s$ is entirely free from either of the chromosome containing the segment $u$. The distance of $s$ and $s^{\prime \prime}$ from the end of the chromosome is so nearly identical that they cannot be distinguished in the rod bivalents in the absence of other configurations.

(3) Segment giving interstitial chiasma. This segment judging from its rarity, is very short, but the infrequency of chiasma formation in it may be due to another cause, namely the reduction in chiasma 
frequency observed while passing inwards from the distal end of a chromosome arm. In Oenothera, as in many other organisms, crossingover and chiasma formation are concentrated in the ends of the chromosomes, so that the absolute length of a chromosome thread giving an average of $x$ chiasmata per nucleus increases as the attachment constriction is approached. Segment $\mathbf{i}$, therefore may be relatively long and yet but rarely disclose its presence by the formation of a chiasma. It is situated in two chromosomes different from those containing the segment $\mathrm{s}$ (cf. Text-fig. $7 \mathrm{~s}$ ). The V-trivalent drawn at Text-fig. $7 \mathrm{~m}$ and PI. 1, Fig. 9, proves that one of the chromosomes containing the interstitial segment has the segment $t$ in its opposite limb. The occurrence with the unequal bivalent (vide infra of a rod bivalent, interstitially associated (as a result of the operation of the pair of $\mathbf{i}$ segments) (Text-fig. $7 t$ ), demonstrates that the chromosome containing $\mathbf{t}$ and $\mathbf{i}$ is a different one from that containing $\mathbf{t}$ and $\mathbf{u}$. This newly identified chromosome may be labelled tC.iD, the order indicating the interstitial position of the $i$ segment; the other chromosome containing $i$ apparently does not contain $\mathbf{t}$, so we may label it provisionally G.iH. This is in harmony with the cases in which the interstitially associated rod bivalent and a terminally associated rod bivalent occur together.

(4) Segment giving unequal bivalent. The configuration resulting from the operation of this segment is of the greatest theoretical importance. The structure of the unequal bivalent is illustrated in Text-figs. $7 a-l, n$ and $t$ and Pl. 1, Figs. 10-12. In it, as a result of chiasma formation in the paired u segments, the two chromatids of each chromosome of the bivalent are unequal in length. At metaphase, one chromatid of each chromosome has a short horizontal distal portion paired with a corresponding portion of the opposing chromatid, the other two chromatids being terminally paired (Text-figs. $7 a-c, f, k, l)$. As a result of this, two of the arms are separated regularly before the other two at the ensuing anaphase (Text-figs. $7 d, e, g, h, n)$; at this stage, the unequal length of sister chromatids is particularly striking. The interpretation offered is that one u segment is terminally placed in its chromosome, while the other is in an interstitial position. Moreover, as in the case of the other segments common to two or more chromosomes, the two are orientated in the same direction with reference to the spindle. If the particles of one were in the reverse order from the particles of the other, an entirely different structure would result (Text-fig. $8 e$ (iii)). Such a structure has been sought for carefully, but it has not yet been found. 
The remainder of Fig. 8 is a diagrammatic history of the two chromosomes through the stage of prophase, ending with the metaphase structure. Text-figs. $8 d$ (i) and $8 d$ (ii) illustrate the theoretical structure of the bivalent at diplotene respectively on the chiasmatype and classical theories of chiasma formation; the corresponding metaphase structures following terminalisation are shown at Text-figs. $8 e$ (i) and $8 e$ (ii). It is, therefore, clear that the observations are quite incompatible with the classical theory that a chiasma is formed as a result of the exchange of partners between the four chromatids involved. The unequal bivalent is another proof that chiasma formation is a result of
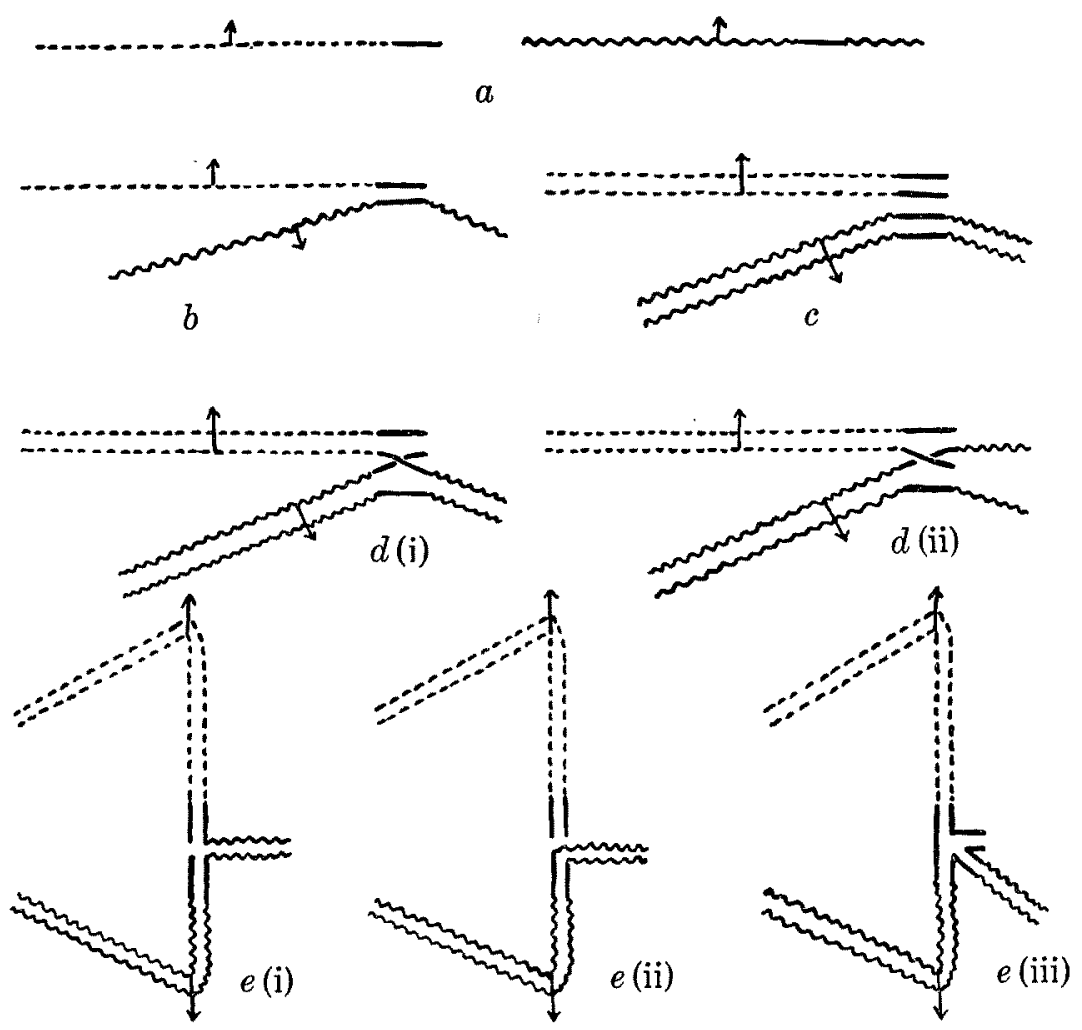

Text-fig. 8. Diagram to show the mechanism of pairing and chiasma formation on (i) the chiasmatype and (ii) the classical theories between two homologous segments of otherwise non-homologous chromosomes in a haploid one segment being terminal and the other interstitial. The segments having the same orientation with respect to the spindle attachment. The metaphase configuration in a case in which the two segments are reversed with reference to one another is shown at (e) (iii). 
cytological crossing-over, with the corollary that only sister chromatids are paired on both sides of the chiasma. Wenrich's (1916) unequal bivalents $B$ and $C$ provide a precisely similar proof. Sax's theory of crossing-over (1930) is negatived by the unequal bivalent, since the particular structure found (Text-figs. $7 b 8 e$ (i)), could be formed on this hypothesis only if two non-compensating chiasmata were formed in the paired segments, followed by breakage at one of them, in the manner postulated by Sax, and subsequent terminalisation of the other. Formation of two chiasmata in such a short paired portion is most unlikely. Further, the absence of the other structural type (Text-fig. $8 e$ (ii)), which would result from the formation of one chiasma formed in the classical manner, is highly significant. For it would be placing undue strain upon the laws of chance to believe that the 23 cells containing an unequal bivalent represent a bad sample of a population in which the only type found is the one that should be the less frequent!

The distribution of the two $\mathbf{u}$ segments among the seven chromosomes has been discussed already and it has been concluded that they occur as follows:-tA.Bu. and $\mathbf{s}^{\prime \prime}$ K.Lu. The trivalent, in Text-fig. $7 l$, suggests that there may be another pair of segments, in two other chromosomes, giving a similar unequal type of association.

A structure closely similar to the trabant found on one of the somatic chromosomes has been seen rather frequently in the meiosis of the haploid. It is drawn at diakinesis in Text-fig. $5 c, d$ and at metaphase $\mathrm{I}$ in Text-fig. $6 \mathrm{~m}$ and $7 q$. Never more than one such trabanted univalent has been seen in any one cell, nor has it been recognised in a bivalent or other multivalent structure. Whether it is really identical with the somatic trabant is uncertain but the resemblance is quite striking.

A peculiar configuration is shown at Fig. $6 o$; the actual manner in which the two chromosomes are associated is difficult to make out and no explanation of the structure can be offered. It is certainly not a ring bivalent of the ordinary type.

Were the chromosomes double precisely in the manner of somatic chromosomes, there should now follow an anaphase separation of the daughter halves of the univalents. This rarely happens and then only when the univalent has remained at the equator of the spindle for a long time and the other chromosomes have reached the poles of the spindle. The attachment constriction, therefore, cannot be split at metaphase though the whole of the rest of the chromosome probably is divided. This is a different situation from that of somatic chromosomes, which separate first at the attachment constriction. 
The chromosomes most often pass, probably at random, to one pole or other of the spindle. Their movement to the poles is by no means co-ordinated chronologically. Incidentally, many of the chromosomes probably have never been at the equator of the spindle, but have had a definite bias towards one or other of the poles ever since diakinesis. This leads to a characteristic scattered arrangement which may be observed in many of the figures. Some commence to move long before others (Text-fig, $9 a$ ), and not infrequently some may be left stranded on the equator giving a scattered arrangement (Text-fig. $9 e$ ). During the passage to the poles, each chromosome moves with its attachment constriction foremost and the general shape is that of a short stout V.
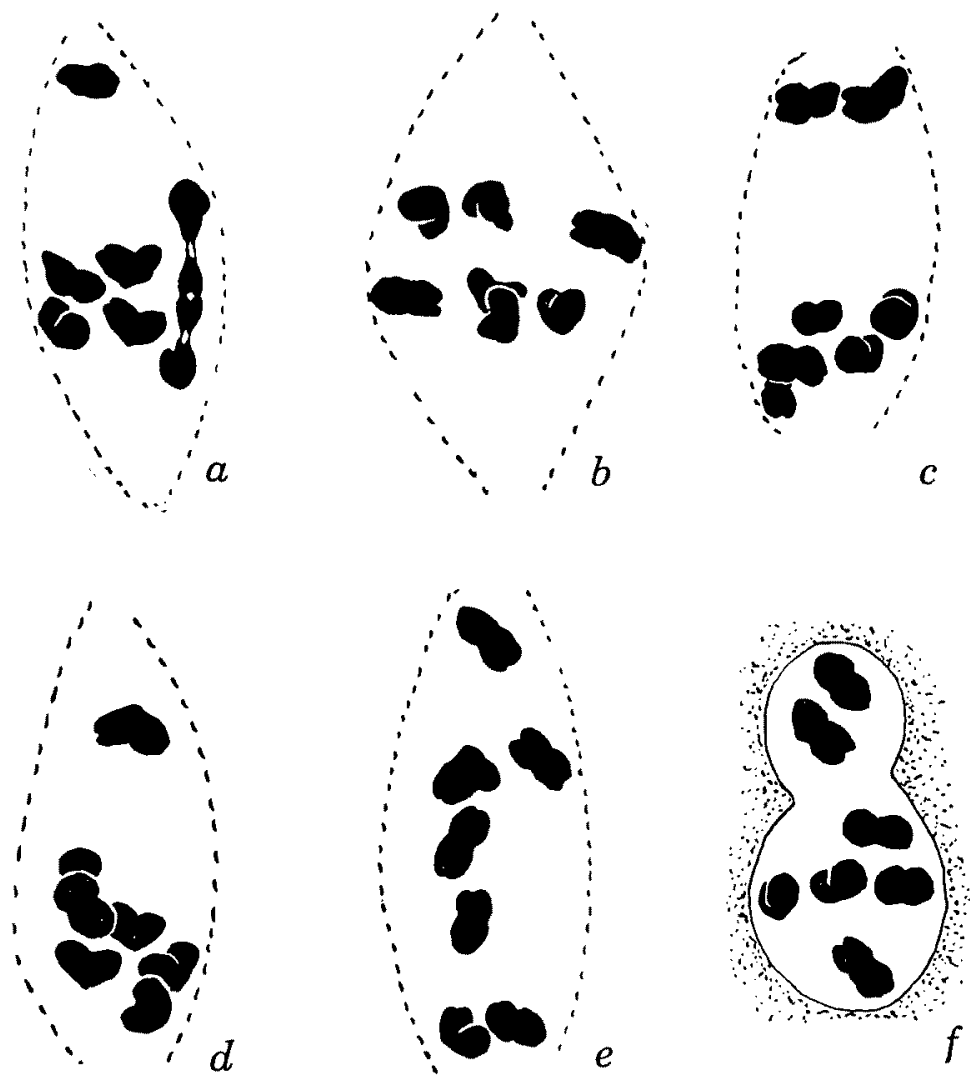

Text-fig. 9. Oe. blandina haploid meiosis ; anaphase I; $(a)$ separation of bivalent with interstitial chiasma; (b) $4+3$ disjunction; $(c) 5+2$ disjunction; $(d) 6+1$ disjunction ; $(e)$ scattered arrangement, some univalents lagging; $(f)$ restitution nucleus following lagging of univalents at anaphase $\mathrm{I} . \times 4,200$. 
The possible disjunctional numbers at anaphase (all actually found) are $7+0,6+1$ (Text-fig. $9 d$ ), $5+2$ (Text-fig. $9 c$ ), and $4+3$ (Text-fig. $9 b$ ), supposing that all the chromosomes pass to one pole or the other. The total numbers of the disjunctional types observed and the proportions expected on a random distribution are shown in Table $4 A$; only anaphases or telophases (before the formation of a nuclear membrane) showing two definite groups passing to, or situated at, either pole have been counted. Corresponding figures have also been presented for interkinesis and division II (Table $4 B$ ). When chromosomes lag at the equator, either three nuclei (see footnote to Table 4) or more commonly a restitution nucleus (Text-fig. $9 f$ ) is formed; hence in a relatively large proportion of cases there is a single interkinesis nucleus in the cell. The $A$ group of figures demonstrates that the movement of the chromosomes in anaphase $I$ is at random. The $B$ group shows a very marked increase in the number of $7+0$ cells, at the expense of the other classes, due entirely to the formation of restitution nuclei.

Table 4

Anaphase I distribution of chromosomes in meiosis of haploid Oenothera blandina and the effect of restitution nuclei.

\begin{tabular}{|c|c|c|c|c|c|}
\hline Stage & & $7+0$ & $6+1$ & $5+2$ & $4+3$ \\
\hline \multirow{3}{*}{$\begin{array}{l}\text { A. Anaphase I } \\
\text { and early } \\
\text { telophase I }\end{array}$} & Observed & 2 & 13 & 41 & 56 \\
\hline & $\begin{array}{l}\text { Calculated on random distribu- } \\
\text { tion of seven chromosomes }\end{array}$ & 1.75 & 12.25 & 36.75 & 61.25 \\
\hline & $\begin{array}{l}\text { Calculated on random distribu- } \\
\text { tion except of two chromo- } \\
\text { somes in } 21.6 \% \text { of cells }\end{array}$ & 1.375 & 11.125 & 36.375 & 63.125 \\
\hline
\end{tabular}

\begin{tabular}{c|c|c|c|c|c}
\hline B. Interkinesis & Observed 1) & 11 & 3 & 11 & 23 \\
\cline { 2 - 5 } and \\
division II & $\begin{array}{c}\text { Calculated on random distribu- } \\
\text { tion of seven chromosomes }\end{array}$ & 0.75 & 5.25 & 15.75 & 26.25 \\
\cline { 2 - 5 } & $\begin{array}{c}\text { Calculated on random distribu- } \\
\text { tion except of two chromo- } \\
\text { somes in 21.5\% of cells }\end{array}$ & 0.6 & 4.825 & 15.625 & 26.950
\end{tabular}

(1) There were also 2 cases of $3+3+1$ and one of $4+2+1$ disjunctional types; these are excluded from the table. 
Two calculations for random distribution have been given, based on two different assumptions. The first supposes that all the seven chromosomes pass to the poles at random; the proportions are easily calculated by comparing the numbers of ways in which $r$ things at a time may be taken from $n$ things, where $r=0-7$ and $n=7$. The second calculation takes account of the cells in which bivalents occur; those amount to about $21.5 \%$ of all the pollen mother cells. The calculation is made by assuming that 7 chromosomes are passing at random in $78.5 \%$ of the cells, and that 5 chromosomes are passing at random in $21.5 \%$ of the cells. In the latter case the two chromosomes constituting the bivalent pass one to each pole, The two results are added together, the totals being the figures shown in the table. The most important point to note is the relatively slight disturbance of randomness produced by the bivalent formation observed. The deviation of the observations from expectation is far greater than the difference to be looked for as a result of pairing of chromosomes.

Emerson (1929) found in haploid Oe. franciscana a marked bias in the direction of $7+0$ and $6+1$ distributions. His data are derived from interkinesis nuclei, so that the deviation from a random distribution can probably be explained on the basis of restitution nuclei. The almost constant occurrence of a bivalent in the Oe. franciscana haploid would probably lead to a greater number of the $6+1$ cases, since one chromosome of the bivalent may be expected to travel away from the main group, which could then form a kind of restitution nucleus.

At interkinesis, a delicate cell plate can usually be made out stretching transversely across the mother-cell between the twe nuclei; this plate is apparently evanescent. Often, too, there is some indication of a furrow, at the periphery, which becomes rather deeper during the second meiotic division. Sometimes the contents of the mother cell are divided into two before the second division is completed ; this may lead to the formation of the binucleated young pollen grains noted below.

Sometimes, the two chromatids of each chromosome going into an interkinesis nucleus appear to separate completely from one another before the nuclear membrane disappears preparatory to the second division. It has not been possible to trace the results of this through anaphase II ; it is uncertain whether any spindle is formed after such an irregularity in the nucleus. The telophase II nuclei (Text-fig. $10 a, b$ ) believed to result from the abnormality, contain an even number of chromosomes, usually 10 or 12 . These nuclei could be interpreted as the result of a post anaphase II restitution nucleus, but that the inter- 
kinesis nuclei show evidence of the other phenomenon. The aberration is not at all fully understood. Briefly, it may be said that separation of the chromosome halves anticipates nuclear division; possibly the nuclear division is then omitted. Apparently the chromosomes have a strong urge to divide, possibly owing to the failure of the division at anaphase I.
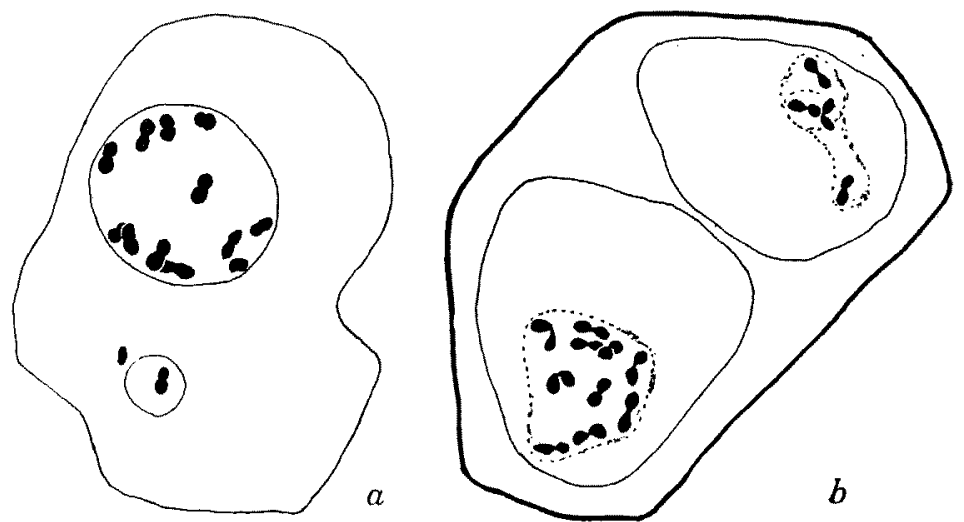

Text-fig. 10. Oe. blandina haploid, telophase II nuclei, possibly the result of chromosome separation without nuclear division. $\times 2,800$.

The second division (homeotypic) is otherwise normal in its essential features, the only other special feature being the frequent occurrence of a single giant spindle (following the formation of a restitution nucleus). The comparative numbers of chromosomes on the spindle at division II (and interkinesis) are recorded above (Table 4). A restitution nucleus may also follow anaphase II, so that triads and monads

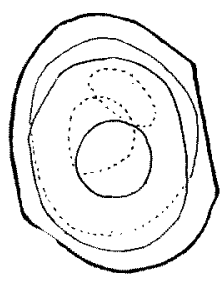

$a$

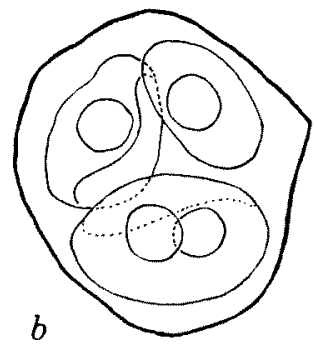

Text-fig. 11. Oe. blandina haploid, "tetrad" stage; (a) diad; (b) triad. Note binucleate condition of two young pollen grains. $\times 2,800$. may be formed. The relative numbers of the various types observed in 180 pollen mothercells at the tetrad stage are :1 monad, 63 diads, 21 triads, 93 tetrads and 2 pentads. In many of the diads (Text-fig. $11 a$ ) and triads (Text-fig. $11 b$ ) one of the cells contains two or rarely more nuclei. This may be the result of the precocious furrowing that sometimes follows 
division I or may indicate some other chronological misfit of the processes of nuclear division and cytokinesis. The 63 diads, therefore; do not by any means all represent the products of restitution nuclei; possibly half of them have that origin.

\section{Observations on Pollen Mother Cells of the Diploid}

The discovery of bivalents and multivalent associations of chromosomes in the haploid at once prompts one to search for corresponding structures, namely quadrivalents and other multivalents, in the diploid. A close examination was rewarded with a limited amount of success. A few other interesting points were also observed and are probably worth recording.

A full account of meiosis in diploid Oe. blandina is given by Gates and Goodwin (1931), who observed parasynapsis at early prophase and who have figured stages that can be interpreted as typical zygotene and pachytene phases. In my material, fixed in precisely the same manner as that of the haploid, good stages from late diplotene to diakinesis have been obtained. Chiasma numbers as high as 4 per bivalent have been observed at late diplotene, but it is usually difficult to follow every bivalent in a given cell. Table 5 summarises the chiasma numbers at late diplotene, diakinesis and metaphase I. The figures prove that the terminal chiasmata characteristic of late diakinesis and metaphase are derived from previously interstitial ones by terminalisation. Further, that the average number of chiasmata per bivalent is reduced between late diplotene and metaphase I; unfortunately it is almost impossible to study the earlier stages. Text-figs. $12 a$ and $b$ show late diplotene stages in bivalents having 4 chiasmata; in one case $(a)$ there are two in each arm, in the second $(b)$ there are three in one arm and a single (terminal)
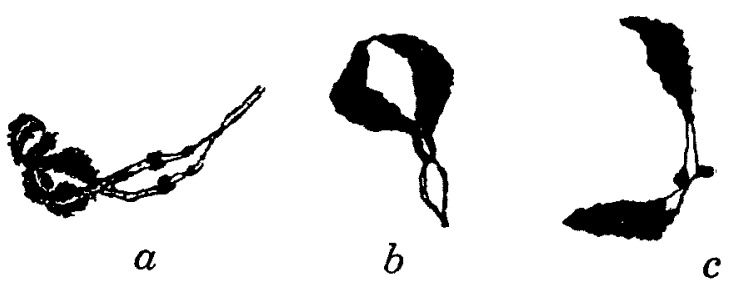

Text-fig. 12. Oe. blandina diploid; bivalents showing interstitial chiasmata; $(a) \&(b)$ late diplotene; (c) diakinesis. $\times 4,200$. one in the other arm. Text-fig. $12 c$, from a diakinesis nucleus, shows a rod bivalent with a sub-terminal chiasma in which the tetrad structure shows clearly. 
Interstitial chiasmata have also been figured by Emerson $(1931 a)$ in a homozygous diploid species.
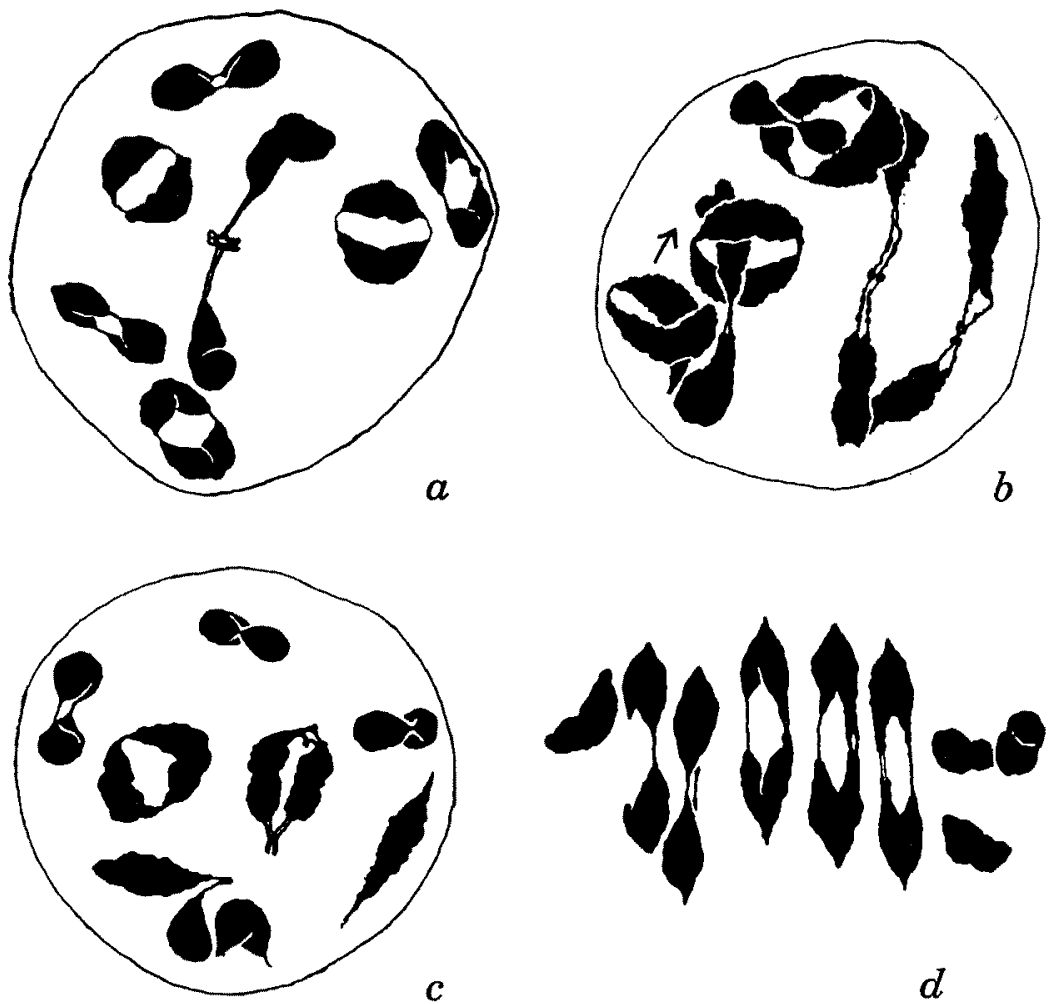

Text-fig. 13. Oe. blandina diploid; (a) diakinesis showing 1 rod bivalent with subterminal chiasma +6 ring bivalents (fixed with Allen's Bouin, note smooth contracted outlines of chromosomes); (b) diakinesis with 4 rod bivalents +3 ring bivalents; (c) diakinesis with 1 rod bivalent +5 ring bivalents +2 univalents; $(d)$ metaphase I with 5 ring bivalents +4 univalents. $\times 4,200$.

As a result of chiasma failure in paired chromosome limbs, rod bivalents (Text-figs. $13 a-c$ ) or less commonly two or more univalents (Text-figs. $13 c-d$ ) may be formed instead of the usual ring bivalents. Gates and Goodwin (1931) have recorded the relative numbers of cases at diakinesis and metaphase, and found an increase in the number of breaks from diakinesis to metaphase. The reason for this is obscure, unless the accuracy of the metaphase counts is disturbed by remarkably early anaphase breakdown of the terminal chiasmata in many cases. Anaphase breaking of terminal chiasmata is not absolutely synchronous 
throughout the fourteen terminal chiasmata in any one cell, and early breakage of quite a small proportion would account for the apparently reduced frequency of terminal chiasmata at metaphase compared with diakinesis.

Table 5

Number of terminal and interstitial chiasmata at meiosis in diploid Oenothera blandina.

\begin{tabular}{l|c|c|c|c|c}
\hline \multicolumn{1}{c|}{ Stage } & $\begin{array}{c}\text { Total no. } \\
\text { chromosomes }\end{array}$ & $\begin{array}{c}\text { Total no. } \\
\text { chiasmata }\end{array}$ & $\begin{array}{c}\text { Total no. } \\
\text { terminal } \\
\text { chiasmata }\end{array}$ & $\begin{array}{c}\text { Av. no. } \\
\text { chiasmata } \\
\text { per pair of } \\
\text { chromosomes }\end{array}$ & $\begin{array}{c}\text { Av. no. } \\
\text { terminal } \\
\text { per pair of } \\
\text { chromosomes }\end{array}$ \\
\hline Late Diplotene & 186 & 208 & 59 & 2.21 & 0.63 \\
Diakinesis & 280 & 262 & 237 & 1.87 & 1.69 \\
Metaphase I & 420 & 401 & 394 & 1.91 & 1.88
\end{tabular}

My material has shown a lower frequency of chiasmata at diakinesis than did that of Gates and Goodwin. This is probably related to different temperature conditions at the time of the two collections of material (which were made in different years). The effect of temperature in altering chiasma frequency (Heilborn, 1930) and genetic crossingover (Plough, 1917) is well established. The two sets of results are

Table 6

Distribution of chiasma failure at diakinesis in diploid

Oenothera blandina.

\begin{tabular}{|c|c|c|c|c|c|c|}
\hline \multirow{2}{*}{ Source of data } & $\begin{array}{l}\text { No. of terminal chias- } \\
\text { mata per nucleus }\end{array}$ & 14 & 13 & 12 & 11 & 10 \\
\hline & $\begin{array}{l}\text { No. of breakages per } \\
\text { nucleus }\end{array}$ & 0 & 1 & 2 & 3 & 4 \\
\hline \multirow{2}{*}{$\begin{array}{l}\text { Gates \& Goodwin (1931); } \\
\text { material collected } \\
\text { in } 1930\end{array}$} & $\begin{array}{l}\text { No. of nuclei (obs.) } \\
\text { Total } 189\end{array}$ & 181 & 8 & - & - & - \\
\hline & No. of nuclei (calc.) & 181 & 7.5 & 0.5 & - & - \\
\hline \multirow{2}{*}{$\begin{array}{c}\text { Catcheside; } \\
\text { material collected } \\
\text { in } 1931\end{array}$} & $\begin{array}{l}\text { No. of nuclei (obs.) } \\
\text { Total } 140\end{array}$ & 65 & 57 & 16 & 1 & 1 \\
\hline & No. of nuclei (calc.) & 67.1 & 48.5 & 16.3 & 3.4 & 0.5 \\
\hline
\end{tabular}

1) Here $\chi^{2}=3.75, n=3$ and $P$ lies between .2 and .3 ; the deviations therefore are not significant. 
compared in Table 6, in which the number of nuclei in each class, calculated on a random distribution, assuming that each terminal chiasma has the same chance of failure, is also shown. The figures strongly suggest that the chiasmata are distributed at random among the fourteen chromosome limbs. The calculation, for example in the case of my own data, was made as follows :-Total number of breaks in 140 nuclei is 96 , i. e. $\frac{96}{140}$ breaks per nucleus. Hence, common probability $=\frac{96}{140 \times 14}=\frac{12}{245}$. The probability of $n$ breaks per nucleus is given by $\frac{114}{|n|(14-n)}\left(\frac{234}{245}\right)^{14-n}\left(\frac{12}{245}\right)^{n}$; and the distribution of the 140 nuclei into the different classes is found easily by multiplying by that figure. The chiasma frequency at diakinesis in my material is $\frac{233}{245}=0.95$ per pair of segments, or 1.9 per bivalent. Calculation from the figures of Gates and Goodwin (1931) gives 0.995 per pair of segments at diakinesis and 0.92 per pair of segments at metaphase representing a loss of nearly one whole terminal chiasma per nucleus between diakinesis and metaphase.

A few multivalent structures have been observed at diakinesis. Establishment of the existence of true quadrivalents in the diploid is complicated by distal interlocking ${ }^{1)}$ (Catcheside, 1931; Gairdner and Darlington 1932) since two distally interlocked bivalents will give a structure simulating a true quadrivalent.

Trivalents cannot be derived from a bivalent and a univalent by any known means of interlocking; hence, the trivalent shown at Textfig. $14 a$ is probably a true multivalent. Formation of quadrivalent types through the action of short homologous segment present in otherwise non-homologous chromosomes can give, theoretically, a definite number of quadrivalent types. The possibilities for the important case of duplicated terminal segments, are represented diagramatically in Text-fig. 15. Of the seven possible quadrivalent types, three (Textfig. $15 e-g$ ) may be formed equally well by distal interlocking of bivalents; these have all been found in the diploid and are drawn at Textfigs. $14 c-e$. The remaining four types (Text-fig. $15 a-d$ ) cannot be derived from bivalents by distal interlocking. Hence, such configura-

1) A distal interlock between two bivalents may be defined as one which arises through one end of one bivalent being caught between two chiasmata terminalising in the same direction in the second bivalent. It is theoretically possible for the two ends of a ring bivalent to be distally interlocked; all four ends of the two ehromosomes will then be associated at one point. 
tions are true multivalents and their occurrence would prove that the duplicated segments can pair independently of the remainder of the chromosome limbs. One case only (Text-fig. $14 b$ ) has been found; it is

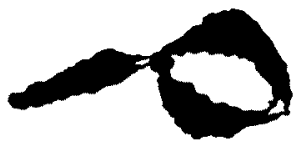

$a$

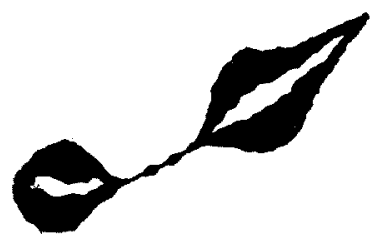

$c$

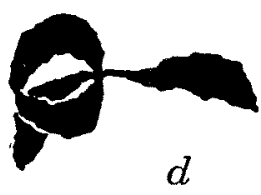

$d$

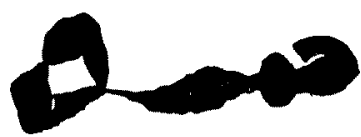

$b$

Text-fig. 14. Oe. blandina diploid; $(a)$ trivalent; $(b)$-(e) quadrivalents. All taken from whole diakinesis nuclei. $\times 4,200$.

a representative of the type shown at Text-fig. $15 c$; incidentally, two of the chromosomes are associated by an interstitial chiasma. The occurrence of multivalents in the diploid, due to the cause giving bivalents in the haploid, may be said to be established; but the bulk of the evidence, though incontrovertible, is not overwhelming.
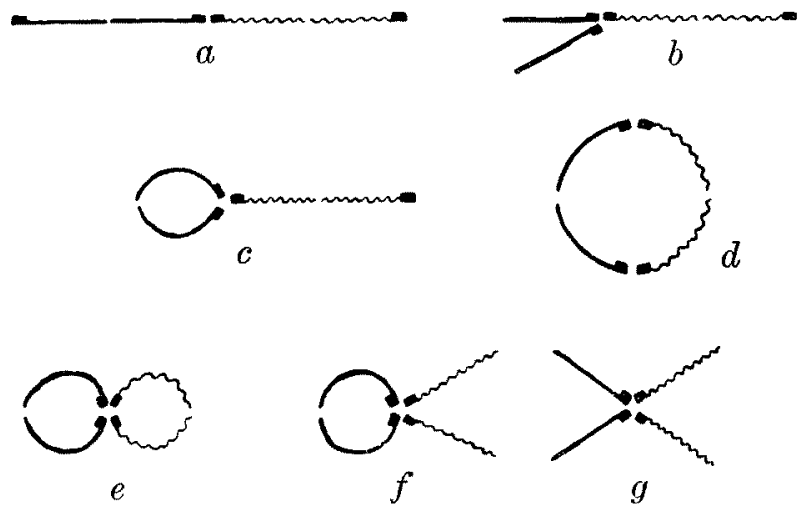

Text-fig. 15. Diagram of the quadrivalent-types theoretically capable of formation from four chromosomes which are structurally tA.B, tA.B, tC.D, and tC.D. Of the seven configurations three $(e-g)$ can also be formed by distal interlocking of two bivalents. 


\section{Discussion}

\section{(i). Reduplication of Segments and Mutation by Structural Change}

The most important result accruing from the present study is the definite establishment of the existence of short homologous segments in different chromosomes of the haploid set. They throw further light on the origin of mutant types in Oenothera, emphasizing the inherent cytological basis of the greater number of them. The mutational types may be classified as follows:-

1. Gene mutations due to an actual chemical change in the gene: Includes rubricalyx (Gates, 1915); vetaurea and funifolia (Shull, 1921); supplena (Shull, 1927) ; bullata (Shull, 1928) ; brevistylis and laevifolia (de Vries, 1901-3); stenophylla and angustifolia (de Vries, 1929).

2. Changes in chromosome number: Includes haploidy (Emerson, 1929 ; Davis \& Kulkarni, 1930 ; Stomps, $1930 \mathrm{a}$ and b ; Gates \& Goodwin, 1930; and above); triploidy (Gates, 1909a); tetraploidy (Gates, 1909 b) ; trisomy (Gates, 1907) ; extra fragments (Håkansson, $1930 \mathrm{~b}$ ) ; and deficiency of a fragment (Sturtevant, 1931).

3. Changes due to crossing-over in complex permanently heterozygotic forms between homologous terminal segments, hence not involving segmental interchange. Includes biennis sulfurea in which the $\mathrm{s}$ of albicans has entered rubens (chromosome configuration given by Cleland, 1926); Renner's strain of biennis in which $S$ has entered albicans (Renner, 1925); suaveolens sulfurea in which $\mathrm{s}$ from albicans has entered flavens (Cleland and Oehlkers, 1930); Lamarckiana. nanella, in which $\mathrm{n}$ from gaudens has entered velans (chromosome configuration given by Sturtevant, 1931 and Emerson, 1931 b).

4. Changes due to crossing-over in complex permanently heterozygotic forms between homologous interstitial segments usually in the differential regions (proximal to the non-homologous terminal segments). These may be grouped into:-(i) crossing-over between non-corresponding segments of members of opposite complexes. Includes

(a) alethal segregates e.g. lutescens from Oe. suaveolens (de Vries, 1918 b ; Renner, 1927; Oehlkers, 1923) and ochracea from Oe. grandiflora (de Vries, 1918 a ; Gerhard, 1929).

(b) primary half-mutants and their secondary alethal segregates e.g. rubrinervis and deserens from Oe. Lamarckiana (Darlington, 1931 b), 
problandina and blandina (de Vries, 1917), erythrina (de Vries, 1919) and rubrisepala (Håkansson, 1930 a). (ii) Crossing-over between corresponding segments of members of the same complex, giving rise to mass mutants e.g. mutants semialta, debilis, rigida, and bilonga of Oe. Reynoldsii (Bartlett, 1915; La Rue and Bartlett, 1917).

The first three categories have long been recognised ; the fourth is much more recent, and its classification is due to Darlington (1931 b). The majority of the cases grouped under class 4 have no cytological proof at present ; actually the cytological basis for a single one only has been described, viz. the origin of the half-mutant rubrinervis from Lamarckiana. The configuration is a "figure of eight" (Darlington, $1931 \mathrm{~b}$ ) and its formation is due to the presence of short homologous segments in non-corresponding segments of chromosomes belonging to opposite complexes. It was observed in Oe. biennis, but probably can be paralleled in Oe. Lamarckiana. This constitutes the only observation proving the presence of relatively translocated interstitial segments in opposing complexes, in Oenothera. ${ }^{11}$

The bivalents, etc., in haploids (Emerson, 1929 and above) give proof of the presence of reduplicated segments in non-homologous chromosomes. Oe. blandina has thrown one mutant only, namely $O e$. spiralis (de Vries, 1917) ; the mutant appeared 4 times in about 3,000 plants, its frequency therefore being $0.1 \%$. It is possible that it can arise through an exceptional cross-over between non-homologous chromosomes, through chiasma formation between reduplicated segments. Reduplicated terminal segments form a mechanism whereby genes may be transferred from one linkage group to another without affecting the pairing properties of the chromosomes concerned.

The interstitially placed segments $\left(s, s^{\prime}, s^{\prime \prime}\right.$ and $\left.i\right)$ provide a mechanism whereby reciprocal translocation or rather segmental interchange could occur. Taking the interstitial segment $i$ as an example, the chromosomes bearing it are respectively C.iD, C.iD, G.iH and G.iH. Exceptional pairing of the $\mathbf{i}$ segment of $\mathrm{CD}$ with that of $\mathrm{GH}$ would give the configuration $\underset{\mathbf{i}}{\mathrm{C}-\mathrm{C}} \mathbf{i - \mathbf { i }}-\mathbf{G}$ i with the possible viable gametes D.D H.H

C.iD + G.iH and C.iH + G.iD, of which the latter is a new one. If the zygote, produced from the mating of C.iH+G.iD with the unchanged gamete type C.iD + G.iH, happened to be viable, and there is

1) A similar structure has been observed in Pisum by Mrs. E. R. Sansome. (1932 unpublished) and a similar configuration described genetically in Datura by Bergner and Blakeslee (1931). 
apparently nothing to prevent its survival, it would give at meiosis a ring of four chromosomes, C.iD-Di.G-G.iH-Hi.C. But the ring mechanism produced has no particular properties (presence of lethals) whereby it would be self-perpetuated; there is no genetic difference apparent between the gametic types C.iD+G.iH and Di.G + Hi.C. Hence probably $50 \%$ of the progeny would be structurally homozygous and with continued self-fertilisation the ring-forming type would be gradually submerged and finally obliterated. Such a type of translocation, therefore, could hardly be of evolutionary significance, at least in producing a constant breeding structural hybrid. It is the secondary result of previous structural heterozygosity (the homozygous strain with the reduplication being a segregate) rather than a possible primary cause of permanent ring formation. It is significant, however, that two strains differing by a single segmental interchange, can be produced, and may be obtained in the progeny, of the haploid. Crossed together, later in their history, they could give a ring-forming type in a similar manner to the parallel cases of Pisum (Pellew \& Sansome, 1931), Campanula (Gairdner \& Darlington, 1930) and Datura (Blakeslee, 1929). This, of course, does not signify or suggest that the segmental interchanges, by which the various races of these plants differ from one another, necessarily arose in this manner. (see below).

The u segment, however, is somewhat different in its effects. Suppose that the chromosomes containing this particular segment are respectively a.buc, a.buc and d.eu, d.eu, the full stop indicating the position of the attachment constriction. Then exceptional crossing-over between a.buc and d.eu will give the new gametic types a.bu+d.euc, a.buc +d.euc, and d.eu+a.bu. The last (d.eu+a.bu) is deficient in a segment and hence would probably be non-viable. Each of the other two translocated types is presumably viable when associated with the unchanged type and, further, each is capable of forming a ring of four chromosomes with the unchanged type. One of them would be a.but ue.d+d-euc +cub.a, capable of giving two structurally homozygous types, in addition to the ring-forming type, which consequently would be gradually eliminated. Exceptional pairing of the large e segment would give the gametic type a.buc +d.euc, similar to the second of the three possible new ones given by the original cross-over. This, with the original unchanged gametic type, would give two bivalents, one a.buc-a.buc and the other unequal d.eu-d.euc. Crossing-over in the second bivalent would then lead to a form possessing a.buc, a.buc and d.euc, d.euc, that is with reduplicated end segments. 
As a result of such structural changes a new form, with a relatively large segment (uc) present terminally in four chromosomes, may be evolved. Competition between the pairing segments will probably lead normally to bivalent formation (a.buc-a.buc and d.euc-d.euc) but relatively frequently the reduplicated segments may pair at random. Pairing between these segments should then lead to quadrivalent formation the possible types of which are those represented diagrammatically in figure 15. The probabilities are that the ring and chain of four chromosomes will be the most frequent of the quadrivalent types. The cytological and genetical properties of Oenothera franciscana suggest that its chromosomes may have the last mentioned structure. It is homozygous (h-franciscana. h-franciscana), giving only one type of gamete (de Vries, 1918 c ; Davis, 1916; Hoeppener and Renner, 1929). The genetic results have always indicated that there is no lethal present, hence any ring mechanism could not be self-perpetuating. In the haploid, there is a rod bivalent, terminally attached, in nearly every microsporocyte (Emerson, 1929) ; this indicates that there is a relatively large terminal reduplicated segment. In the diploid, either seven ring pairs of chromosomes (Kulkarni, 1929 ; Sturtevant, 1931) or a ring of four chromosomes and five ring pairs (Cleland, 1922; Hoeppener and Renner, 1929) have been reported. Cleland (1922) further states that the ring, seen at diakinesis, breaks up at metaphase I into two ring pairs; this is unlikely and is not corroborated by other workers. It is interesting, however, in that it indicates a certain amount of variability, in the directions expected, in one and the same plant. A further examination of Oe. franciscana from this view point may yield the quadrivalent types postulated (see Fig. 15).

\section{(ii) Translocation and its Mechanism}

Much of the mutation in the genus Oenothera depends, as we have seen, upon structural complexity of the chromosomes which must have arisen from the non-complex condition through the occurrence of translocation. That translocation can occur under controlled experimental conditions is well known. It may arise either spontaneously, as in Drosophila (Sturtevant and Dobzhansky, 1930), or by the action of $\mathrm{X}$-rays, when its frequency is greatly increased, as in Drosophila (Muller and Altenburg, 1930; Dobzhansky, 1929) and Zea Mais (Stadler, 1931). There is an alteration in the constitution of the linkage groups (Stadler, 1931; Brink, 1929; Brink and Cooper, 1931) correlated with 
the formation of a ring of four chromosomes (Randolph unpublishedcited by Stadler, 1931; Burnham, 1930; Mc Clintock 1930). The four paired limbs of the ring-forming chromosomes further correspond in size (Cooper and Brink, 1931). Meiosis, in flies heterozygous for translocations, has not been reported upon in Drosophila. In the Diptera, however, a clear indication of the homologies of the chromosomes is given by the secondary pairing showing in somatic metaphase plates. Sturtevant and Dobzhansky (1930), for instance, have obtained reciprocal translocations between chromosomes II and III in Drosophila. In somatic cells of flies having one normal second, one normal third, and the two reciprocally translocated chromosomes, the four chromosomes frequently form a 4-starred ring.

The question arises, what is the mechanism by which segments are transferred from one chromosome to another? Apparently all effective translocation is reciprocal, that is segments are mutually exchanged between two non-homologous chromosomes. In all the translocations known, the order of the genes in the exchanged segments, with reference to the spindle attachment, is not altered. Hence, the proximal end of a segment is still proximal to the attachment in the new alliance. Segmental interchange with the origin of a lethal mechanism has been described in theory (Darlington, $1931 \mathrm{~b}$ ). He supposes exceptional pairing between relatively translocated interstitial segments, in a form having the constitution A.xB, A.B, C.xD, C.D, the resulting ring having the structure A.xD-D.C.-C.xB-B.A. The occurrence of pairing in Oenothera haploids may be said to support this scheme, since the latter obviously requires the presence of reduplications, in any particular chr mosome complex, as a direct result of the production of a ring-complex mechanism.

Not all reciprocal translocations, however, are self perpetuating in the heterozygous condition; in other words, a proportion of the pro. geny, amounting theoretically to $50 \%$, are homozygous, so that in the absence of any selective benefit conferred by the heterozygous condition of the translocation, such individuals that possess it will be slowly eliminated from the general population. No lethal mechanism, therefore, is involved in such cases but solely a reorganisation in structure of certain of the chromosomes. It is conceivable that the translocation may itself be lethal, as in Drosophila (Sturtevant and Dobzhansky, 1930); the heterozygous condition will then have a correspondingly higher survival value. 
In many organisms there is a characteristic amount of interlocking of rings, either of two or more chromosomes; the phenomenon appears to be exceptionally frequent in Oenothera (Catcheside, 1931). It must arise from entangling of the pairing threads at zygotene; hence, at pachytene, the chromatids of non-homologous chromosomes are intimately associated in the manner of paired segments and at a time when crossing-over normally takes place between them. Any coincidence of breaks for the process of crossing-over, in non-homologous associated threads, renders possible a new structural arrangement of them. This is a likely origin of reciprocal translocations, particularly since irradiation of sex cells results in an increase in the frequency of translocations. The radiations cause a large amount of breakage in the chromosomes, so that the threads in any intimate contacts between nonhomologous chromosomes will stand a good chance of breakage with subsequent reunion at random.

A diagrammatic scheme of the mechanism of origin of translocations from interlocks is given in Text-fig. 16. There are two types of interchange which must be distinguished: (I) that in which the spindle attachments lie on the same side of the point of exchange and (II) that in which the spindle attachments lie on opposite sides of the point of exchange. The latter arrangement results (see metaphase I configuration Text-fig. 16, II (iii)) in two new chromosomes, onè deficient in a segment and without an attachment, the other made up of more than two half chromosomes and with two attachments. Neither chromosome would be mechanically competent at mitosis. The chromosome with two attachments would probably lag, and perhaps fragment, so disrupting the normal sequence of events. This type is thus lethal in itself and need not be considered further, except to point out that it should occur in half of the translocations on the supposition that these are at random. It has never been found genetically, probably owing to its unsound structural basis, but may perhaps be seen at meiosis following irradiation.

The first type of interchange is more important, resulting in a new gametic type, in which the chromosomes are segmentally interchanged. Moreover, the new chromosomes are mechanically and physiologically competent and, in conjunction with an unaltered gamete, can give a type which would have a ring of four chromosomes at meiosis. The mechanism of its origin is depicted at Text-fig. 16 I (i)-(iii). Suppose that the two original chromosomes in a particular strain I are respectively abc. def and ghk. lmo. Then, the new chromosomes are respec- 


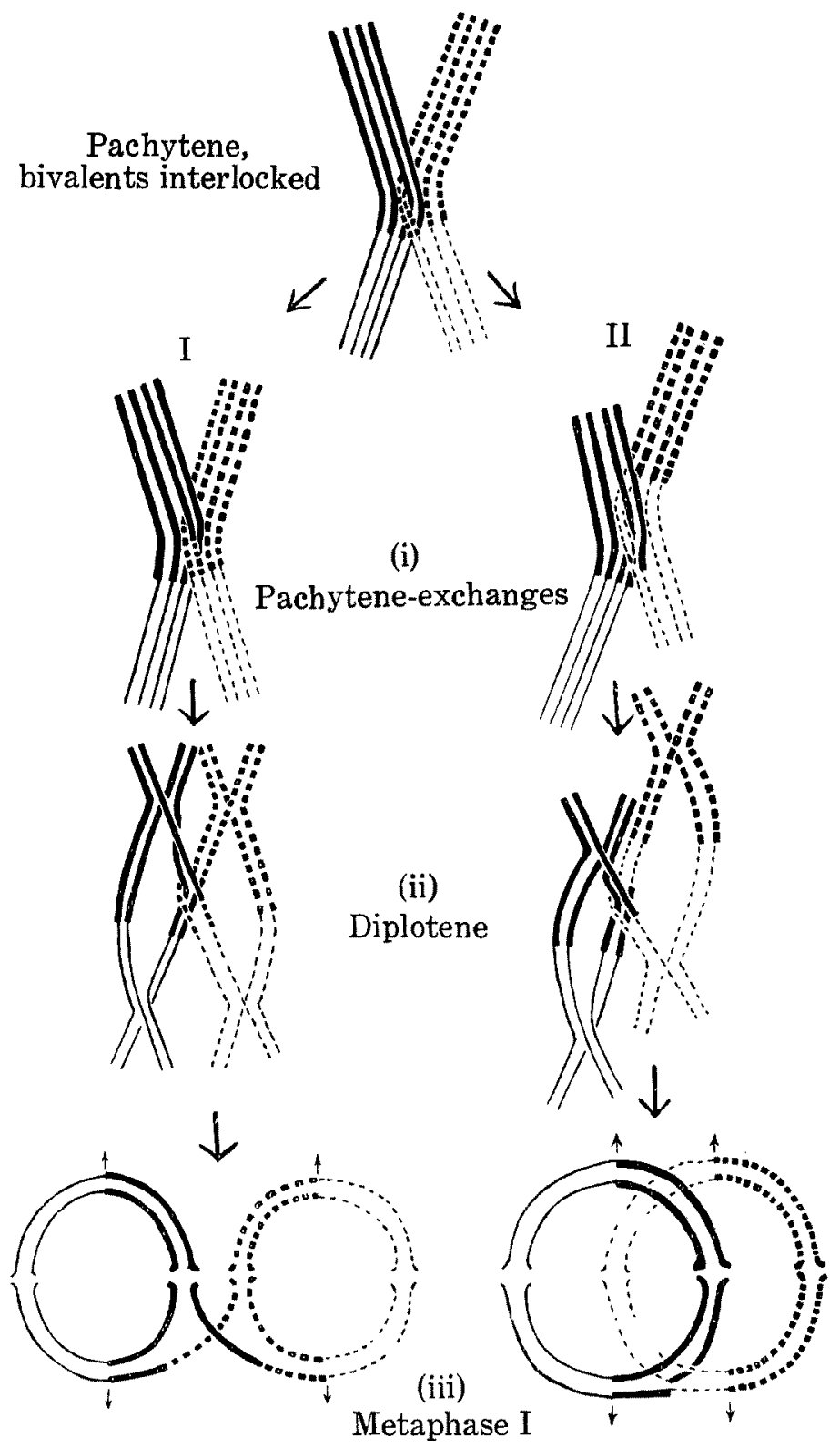

Text-fig. 16. Diagram of the mechanism of reciprocal translocation between two nonhomologous chromosomes as a result of interlocking. Description in text. 
tively abc. dmo and ghk. lef while the ring produced is abc. dmo-oml. khg-ghk. lef -fed. cba. Probably the translocation is capable of existence in the homozygous state, the ring-forming type gradually dying out. A new race (strain II) with its chromosomes abc. dmo, abc. dmo, ghk. lef, ghk. lef will have been established. Further interchanges. with other bivalents would increase the size of the rings in the strain heterozygous for the exchange.

Though this is not a self-perpetuating ring mechanism, it is interesting to note that interstitial segments are present in opposite complexes in non-corresponding positions in chromosomes containing identical end segments. Crossing-over in these segments will result in a. new segmental interchange, in this instance back to the original chromosome type. This is the basis of the exchange believed to result in the segregation of alethal types from complex heterozygotic forms e.g. of lutescens from Oenothera suaveolens (see mutational types 4 (i) (a) above).

The same pair of chromosomes may undergo reciprocal translocations in a variety of other ways. For instance, segment a may be exchanged with segment gh giving ghbc. def +ak. Imo, a type of structure that may become fixed in the homozygous condition (strain III). Oenothera species interbreed freely and there is no doubt that the primitive forms had a similar property. Hence, we might expect that the structurally different strains II and III would cross at some time. The chromosomes will pair two by two as follows abc. dmo-ak. 1mo and ghbc. def-ghk. lef. We may rename them for convenience AxP-AyB and $\mathrm{CxD}-\mathrm{CyD}$, where $\mathrm{A}=\mathrm{a}, \mathrm{B}=\mathrm{mo}, \mathrm{C}=\mathrm{gh}, \mathrm{D}=\mathrm{ef}, \mathrm{x}=\mathrm{bod}$ and $\mathbf{y}=\mathbf{k l}$. Exceptionally the $\mathbf{x}$ or the $\mathbf{y}$ segments may pair and produce segmentally interchanged chromosomes, e.g. AxD + CxB. Such a gamete, provided the $\mathbf{x}$ reduplication was not lethal, would pair at random with the four types of gametes produced from the hybrid: $\mathrm{AxB}+\mathrm{CxD}, \mathrm{AxB}+\mathrm{CyD}, \mathrm{AyB}+\mathrm{CxD}$ and $\mathrm{AyB}+\mathrm{CyD}$. The only zygotic type containing two and only two representatives of each chromosome segment is $\mathrm{AxD}-\mathrm{DyC}-\mathrm{CxB}-\mathrm{ByA}$. This zygotic type answers to the requirements of the Oenothera mechanism in the following particulars:

(1) Its chromosomes form a regular ring at meiosis through pairing of their end segments.

(2) It is a structural hybrid giving only two gametic types $\mathrm{AxD}+$ CxB and DyC + ByA, in addition to the other unaltered chromosomes. 
(3) The chromosomes responsible for a particular gametic type occupy alternate positions in the ring.

(4) Each chromosome consists of two end segments which operate in pairing and a middle differential region which includes the spindle attachment. The middle regions of the chromosomes, making up a particular gametic type, form the differentials in a Renner factor-complex and normally are unpaired.

(5) Neither gametic type is capable of existing in the homozygous condition since both are deficient in a segment.)

(6) In view of the difference in genetic requirements of megaspore and microspore (Renner, 1919, 1921) it is possible that one gametic type has an advantage on the female side while the other may be the only one active on the male side.

(7) It accounts for the presence of interstitial homologous segments in non-homologous chromosomes belonging to the same complex.

It fails however to account for the presence of interstitial homologous segments in non-homologous chromosomes belonging to opposite complexes. With later exchanges between the ring and bivalents outside it, segments so placed will appear. For example, suppose an exchange between DyC and a chromosome EzF occurs to give the new chromosome DyE and $\mathrm{CzF}$; the resulting zygote will have a ring of six chromosomes, viz. AxD-DyE-EzF-FzC-CxB-ByA. Other exchanges may space homologous interstitial segments still further apart around the ring.

The theory is, therefore, that reciprocal translocations involving two particular non-homologous chromosomes can give rise to homozygous strains differing in the segmental structure of their chromosomes. These, on crossing, may give a form having pairs of chromosomes, a member of one pair having an interstitial segment in common with a member of a second pair. This allows segmental interchange with the origin of a ring mechanism in which the two gametic types are structually unlike, but complementary in character. It is essentially

1) In this connection it is perhaps significant that most Oenothera haploids have been derived from homozygous forms viz. Oe. franciscana (Emerson, 1929; Davis and Kulkarni 1930 ; Stomps, 1930 a), Oe. Hookeri (Stomps, 1930a), Oe. argillicola (Stomps, $1930 \mathrm{~b}$ ) and Oe. blandina (above). In Oe. rubricalyx, which gave one haploid (Gates \& Goodwin, 1930), both complexes are functional on the female and male side. There is practically no difference between the two complexes, but they are not viable in the homozygous condition probably owing to the action of a balanced lethal mechanism (Gates and Catcheside, 1932 unpublished). 
an extension, in order to account for the appearance of relatively translocated interstitial segments, of the theory postulated by Darlington $(1931 \mathrm{~b})$. The origin of the Oenothera mechanism proceeds originally from reciprocal translocations, subsequent crossing with defined segmental interchanges in the hybrid produced, and the establishment of the ring-complex mechanism in the $F_{1}$ generation of the hybrid. Later increases in the size of the ring occur (1) by exchanges between the ring and bivalents, (2) by crossing with forms bearing other translocations, (3) by a combination of the two processes.

\section{(iii) Prophase : Competition Between Segments at Zygotene : Contraction of Chromosomes}

It is now generally recognised that pairing between chromosomes is dependent upon particulate attraction between like portions. Allelomorphs, therefore, do not pair because of their innate properties, but because adjacent genes are alike and therefore do pair. Unlike portions may be either passive towards one another or perhaps actually exert a mutual repulsion. A repulsion between unlike segments would be likely to reduce the amount of pairing and therefore crossing-over and chiasma formation in adjacent homologous regions of the same chromosome. This would be comparable to the reduction in cross-over values shown in the broken limb of the third chromosome in translocations involving the third and fourth chromosomes of Drosophila melanogaster (Dobzhansky, 1929, 1930). Rhoades (1931) has found a considerable reduction in crossing-over in the left limb of the second chromosome in females carrying a translocation in which a small interstitial piece had been removed and attached to the $\mathrm{Y}$ chromosome. The genetical length of the translocation fragment is 1.1 to 4.1 map units. Near to the centre of the chromosome this signifies a relatively long piece of the chromosome (cf. Dobzhansky, 1930), so that the homologies are discontinuous over a relatively considerable distance and pairing will be correspondingly affected. Interference with pairing is also exhibited in XXY females carrying two normal second chromosomes and the extra piece of the second attached to the $\mathrm{Y}$ chromosome.

A variety of facts suggest that the relative lengths of segments is of prime importance in pairing :-

1. In the haploid (see above), short reduplicated segments pair frequently, producing 281 chiasmata in 1186 nuclei. In the corresponding diploid these segments pair extremely rarely. 
2. In structural hybrids, e.g. Oenothera, pairing is normally confined to the end segments of the chromosomes; pairing between interstitial segments is exceptional (Darlington, $1931 \mathrm{~b}$ ).

3. In the diploid hybrid Primula Kewensis, the parental verticillata chromosomes regularly pair with those from floribunda, but in the tetraploid or rather amphidiploid, corresponding quadrivalents are rare (Newton \& Pellew, 1929).

Failure of a relatively short segment to find a mate must be ascribed to its smallness in comparison with adjacent larger segments. The two types will seek to pair with entirely different chromosome regions, unrelated structurally, so that the larger segments exerting a correspondingly larger attraction will rarely lose in the competition at zygotene. With an approach towards equality in size, the smaller element may not be at so great a disadvantage.

The nucleus in Oenothera, and probably in many other dicotyledons, appears to become more or less polarised at the prophase of meiosis; the polarisation is exaggerated in imperfectly fixed preparations, the well-known first contraction, synaptic or synizetic knot resulting. The polar focus appears to be the nucleolar region as shown in the haploid at zygotene. This feature may serve to explain the peculiar attachments of chromosome threads to the nucleolus observed by various authors (e.g. Latter, 1926). In both the haploid and diploid material, the attachments observed, ranging in number from none to several in each nucleus, suggest a chance contact rather than a definite connection having a special physiological significence. Frequently, one or more threads may be observed in contact with the nucleolus over a rather considerable distance. Incidentally, it seems unlikely that any chance contact can have a special physiological significance in determining the transference of material from the nucleolus to the chromosomes. Each particle (gene) of a chromosome has a specific structure and order in the chromosome which must be preserved from one cell generation to the next. This is best carried out by a process of copying, the necessary constituent molecules being selected from the medium (karyolymph) which bathes the chromosomes. Passage of raw materials along individual threads from one particle to the next seems a rather unsatisfactory mechanism and one difficult to imagine as a possible result of evolution.

Polarisation of leptotene chromosomes will lead to a closer approach of the ends than of the middle portions. It would therefore favour the pairing of end segments in competition with interstitial segments. 
Middle segments of bivalents would pair last of all. This is in harmony with the evidence from interlocking and may also be correlated with the concentration of chiasmata in the distal portions of the pairing segments.

It has been mentioned above that stages in prophase contraction of the chromosomes at meiosis, show that those bodies commence condensation at their centres apparently at the attachment constriction. Such an effect it was stated could be brought about by the revolution of the spindle-fibre attachment constriction about the long axis of the chromosome, the free ends of the chromosome being relatively stationary. The viscosity of the medium in which the chromosomes are lying would probably interfere effectively with transmission of the turning moment to the ends of the chromosome during the earlier stages. The reduction in transmission would increase progressively from the attachment constriction outwards; hence, coiling of the chromosome thread (chromonema) would follow in such a way that the first coils were close to the constriction and successively later ones further out, the ends of the chromosomes finally being coiled. Transmission of the twist and consequent coiling of the thread necessarily implies a definite degree of coherence between the constituent particles. Moreover, a particular face arrangement of the genes is perhaps of the greatest importance, since there may be a restriction on which face may be the basis of a duplicate copy. When coiling is complete, the contracted coiled arrangement may be maintained by the envelope (or matrix) of the chromosome. If this is a correct explanation of contraction, the coils should be in opposite directions on the two sides of the spindle attachment.

\section{Summary}

A new haploid Oenothera, derived by parthenogenesis from the diploid form as a result of cross-pollination of a flower of the diploid, has been described with special reference to its meiosis. The diploid (Oe. blandina) is homozygous, having seven pairs of chromosomes. The haploid plant shows seven univalents in $80 \%$ of the pollen mothercells, and various bivalent, trivalent and quadrivalent configurations of chromosomes in the re naining $20 \%$ of cells. Corresponding multivalents have been seen in the diploid. Tue associations of chromosomes in the haploid prove the presence of reduplicated segments in the chromosome complement. In one case, the reduplicated segment 
is terminal in one chromesome and interstitial in the other. The unequal configuration produced proves that chiasma formation is associated with and is a direct result of cytological crossing-over; such a configuration would lead to reduplication of end segments.

The significance of the reduplications in relation to segmental interchange, translocation and the origin of a self-perpetuating ringmechanism is discussed. Proofs of various other principles are given, including (i) the random segregation of chromosomes at anaphase I in the haploid, (ii) the disturbance in the random distribution caused by lagging of chromosomes and subsequent formation of restitution nuclei, (iii) terminalisation of chiasmata in the diploid, (iv) random occurrence of chiasma failure in the diploid. The arrest of terminalisation, due to a change in the linear homologies of the chromosomes, is clearly established by the pairing phenomena in the haploid.

\section{Description of Plate 1}

The photomicrographs were taken by Mr. C.S. Semmens, to whom I am much indebted for the skill and care exercised. A vertical bellows camera was used and enlargements were made from the negatives. $A_{12}^{x}$ inch N.A. 1.3 achrom. oil-imm. lens was used in conjunction with a $\times 6$ ocular; the source of illumination was a pointolite, with a Wratten green filter interposed. The magnifications given are approximate.

Fig. 1. Polar metaphase I, showing 7 univalents. $\times 2200$. Drawn at Text-fig. $6 a$.

Fig. 2. Polar metaphase $I$, showing 1 bivalent and 5 univalents. $\times 2200$. Drawn at Text-fig. $6 b$.

Fig. 3. Profile metaphase I, showing rod bivalent with subterminal chiasma. $\times 2200$.

Fig. 4. Profile metaphase $I$, showing 2 rod bivalents. $\times 2200$.

Fig. 5. Profile metaphase I, showing 2 rod bivalents in L. H. cell and 1 rod bivalent in R. H. cell. $\times 1800$.

Fig. 6. Profile metaphase I, showing 2 rod bivalents. $\times 1800$.

Fig. 7. Profile metaphase I, showing ring bivalent. $\times 2900$. Drawn at Text-fig. $7 q$.

Fig. 8. Profile metaphase $I$, showing Y-trivalent. $\times 2900$. Drawn at Text-fig. 70 .

Fig. 9. Profile metaphase I, showing V-trivalent with an interstitial chiasma. $\times 1800$. Drawn at Text-fig. $7 \mathrm{~m}$.

Fig. 10. Profile metaphase I, showing unequal bivalent. $\times 2200$. Drawn at Textfig. $7 a b$.

Fig. 11. Profile metaphase I, showing V-trivalent involving unequal chiasma. $\times 1800$. Drawn at Text-fig. $7 \mathrm{~h}$.

Fig. 12. Profile metaphase I, showing V-trivalent involving unequal chiasma. $\times 1800$. Drawn at Text-fig. $7 n$. 


\section{Bibliography}

Bartlett, H. H., 1915. Mutation en masse. Amer. Nat., 49 : 129-39.

Beadle, G.W., 1931. A gene in maize for supernumerary cell divisions following meiosis. Cornell Univ. Agric. Ex. Stat., Memoir 135, 12 pp.

Bergner, A. D. and Blakeslee, A. F., 1931. Proc. Nat. Acad. Sci., 18: 151.

Blakeslee, A. F., 1929. Cryptic types in Datura. J. Hered., 20: 177-90.

Boveri, T., 1905. Zellen-Studien. V. Ưber die Abhängigkeit der Kerngröße und Zellenzahl der Seeigel-Larven von der Chromosomenzahl der Ausgangszellen. Jena.

Brink, R. A., 1929. The occurrence of semisterility in maize. J. Hered., $20: 266-9$.

- and Cooper, D. C., 1931. The association of semisterile-I in maize with two linkage groups. Genetics, $16: 595-628$.

Burnham, C. R., 1930. Genetical and cytological studies of semi-sterility and related phenomena in maize. Proc. Nat. Acad. Sci., 16: 269-77.

Catcheside, D. G., 1931. Critical evidence of parasynapsis in Oenothera. Proc. Roy. Soc., B 109: 165-84.

Cleland, R. E., 1922. The reduction divisions in the pollen mother cells of Oenothera franciscana. Amer. J. Bot., 9: 391-414.

- 1926. Meiosis in the pollen mother cells of Oenothera biennis and Oenothera biennis sulfurea. Genetics, $11: 127-62$.

- and Oehlkers, F., 1929. Erblichkeit und Zytologie verschiedener Oenotheren und irher Kreuzungen. Jahrb. f. wiss. Bot., 73: 1-124.

Cooper, D. C. and Brink, R. A., 1931. Cytological evidence for segmental interchange between non-homologous chromosomes in maize. Proc. Nat. Acad. Sci., $17: 334-48$.

Darlington, C. D., 1931a. Meiosis. Biol. Rev., 6: 221-64,

- 1931b. The cy tological theory of inheritance in Oenothera. J. Gen., 24 : 405-74.

Davis, B. M., 1916. Hybrids of Oenothera biennis and Oenothera franciscana in the first and second generations. Genetics, 1: 197-251.

- and Kulkarni, C. G., 1930. The cytology and genetics of a haploid sport from Oenothera franciscana. Genetics, $15: 55-80$.

Dobzhansky, T., 1929. Genetical and cytological proof of translocations involving the third and fourth chromosomes of Drosophila melanogaster. Biol. Zentralbl., 49: 408-19.

- 1930. Translocations involving the third and the fourth chromosomes of Drosophila melanogaster. Genetics, $15: 347-99$.

Emerson, S. H., 1929. The reduction division in a haploid Oenothera. La Cellule, 39 : $159-65$.

-1931a. Parasynapsis and apparent chiasma formation in Oenothera. Amer. Nat., 65 : 551-5.

$-1931 b$. Genetic and cytological studies on Oenothera. II. Certain crosses involving Oe. rubricalyx and Oe. franciscana sulfurea. Zeits. f. ind. Abst.-u. Vererbungsl., 59 : 381-94.

Gairdner, A. E. and Darlington, C. D., 1930. Structural variation in the chromosomes of Campanula persicifolia. Nature, 125: 87.

- -1932. Ring formation in diploid and polyploid Campanula persicifolia. Genetica, 13: $113-50$.

Gates, R. R., 1907. Preliminary note on pollen development in Oenothera lata and its hybrids. Science, $25: 259-60$.

-1909 a. The behavior of the chromosomes in Oenothera lata $\times$ Oenothera gigas. Bot. Gaz., 48 : 179-99.

$-1909 \mathrm{~b}$. The stature and chromosomes of Oenothera gigas de Vries. Arch. f. Zellforsch., $3: 525-52$. 
Gates, R. R., 1915. On the origin and behaviour of Oenothera rubricalyx. J. Gen., 4: 353-60.

- and Catcheside, D. G., 1932. Gamolysis of some new Oenotheras. J. Gen., 26: $143-78$.

- and Goodwin, K. M., 1930. A new haploid Oenothera, with some considerations on haploidy in plants and animals. J. Gen., 23 : 123-56.

Gerhard, K., 1929. Genetische und zytologishe untersuchungen an Oenothera grandi. flora Ait. Jena. Zeits. f. Nat., 64: 283-338.

Håkansson, A., 1930a. Die Chromosomenreduktion bei einigen Mutanten und Bas. tarden von Oenothera Lamarckiana. Jahrb. wiss. Bot., 358-402.

-1930b. Zur Zytologie trisomischer Mutanten aus Oenothera Lamarckiana. Hereditas, 14: 1-32.

Hedayetullah, S., 1931. On the structure and division of the somatic chromosomes in Narcissus. J. Roy. Micr, Soc., $51: 347-86$.

Heilborn, O., 1930. Temperatur und Chromosomen-Konjugation. Svensk. Bot. Tidskrift, $24: 12-25$.

Hoeppener. E. and Renner, O., 1929. Genetische und zytologische Oenotherenstudien. Botan. Abhandl., 15: 1-86.

Janssens, F. A., 1924. La chiasmatypie dans les insectes. La Cellule, 34: 133-359.

Kuhn, E., 1930. Pseudogamie- und Androgenesis bei Pflanzen. Der Zùchter, 2: 124-36.

Kulkarni, C. G. 1929. Meiosis in Oenothera franciscana. Pap. Mich. Acad. Sci. and Lett., 9: 223-6.

Lang, W. H., 1909. A theory of alternation of generations in archegoniate plants based upon the ontogeny. N. Phyt., 8:1-12.

La Rue, C. D. and Bartlett, H. H., 1927. Matroclinic inheritance in mutation crosses of Oenothera Reynoldsii. Amer. J. Bot., 3 : 119-44.

Latter, J., 1966. Pollen development in Lathyrus odoratus. Ann. Bot., 40: 277.

Lindstrom, E. W. and Koos, K., 1931. Cyto-genetic investigations of a haploid tomato and its diploid and tetraploid progeny. Amer. J. Bot., 18: 398-410.

McClintock, B., 1930. A cytological demonstration of the location of an interchange between two non-homologous chromosomes of Zea Mais. Proc. Nat. Acad. Sci., 16: 791-6.

Muller, H. J. and Altenburg, E., 1930. The frequency of translocations produced by $\mathrm{X}$-rays in Drosophila. Genetics, 15 :

Newton, W. C. F. and Pellew, C., 1929. Primula Kewensis and its derivatives. J. Gen., 20 : 405-67.

Oehlkers, F., 1923. Vererbungsversuche an Oenotheren, II. Zeits. f. ind. Abst.-u. Vererbl., 31 : 201-60.

Pellew, C. and Sansome, E. R. 1931. Genetical and cytological studies on the relations between Asiatic and European varieties of Pisum sativum. J. Gen., 25: 25-54.

Plough, H. H., 1917. The effect of temperature on crossing-over in Drosophila. J. Exp. Zool., 24: 147-209.

Renner, O., 1919. Zur Biologie und Morphologie der männlichen Haplonten einigen Önotheren. Zeits, f. Bot., 11 : 305-80.

- 1921. Heterogamie im weiblichen Geschlecht und Embryosackentwicklung bei den Önotheren. Zeits. f. Bot., 13: 609-21.

- 1925. Untersuchungen über die faktorielle Konstitution einiger komplexheterozy* gotischer Oenotheren. Biblioth. Genet., 9: 1-168.

- 1927. Ưber eine aus Oenothera suaveolens durch Bastardierung gewonnene homozygotische lutescens-Form. Hereditas, 9: 69-80.

Rhoades, M. M., 1931. A new type of translocation in Drosophila melanogaster. Genetics, 16 : $490-504$.

Sansome, E. R., 1932. Segmental interchange in Pisum sativum. Cytologia, 3: 200-19. 


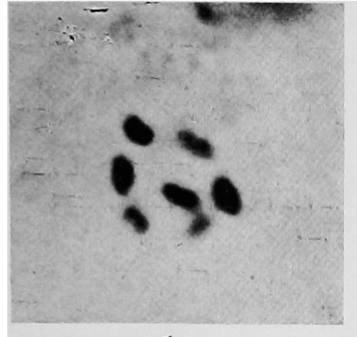

1

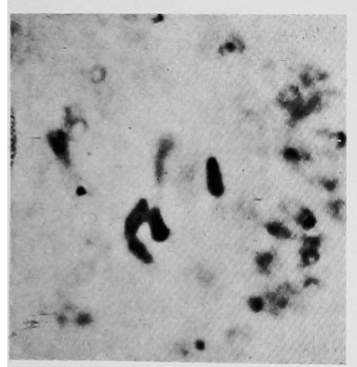

4

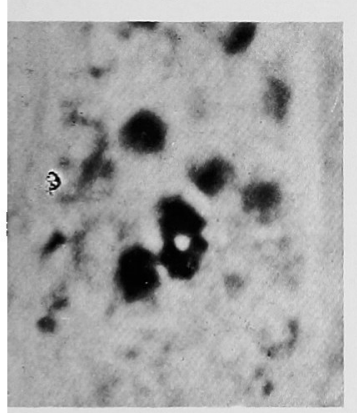

7

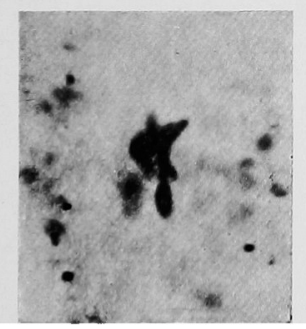

10

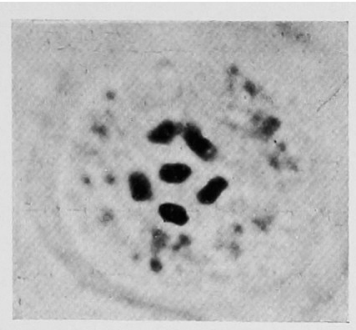

2

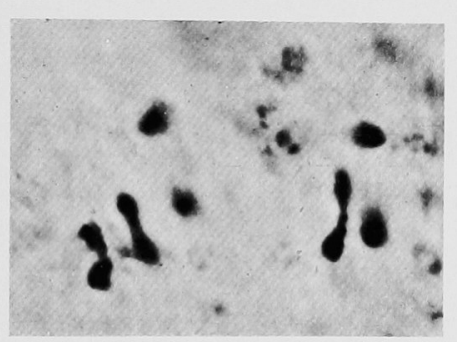

5

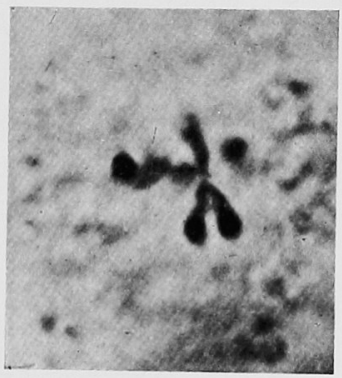

8

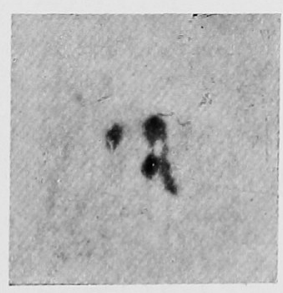

11

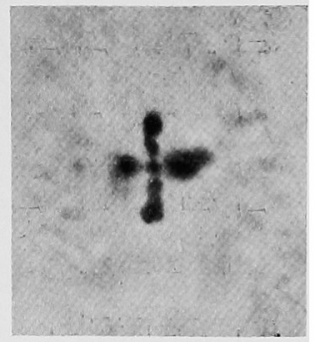

3

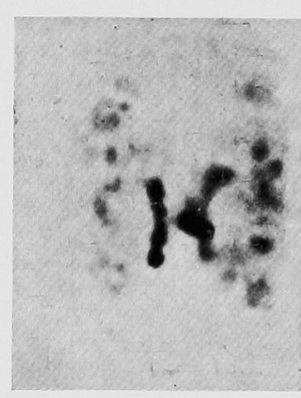

6

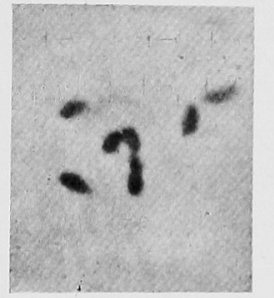

9

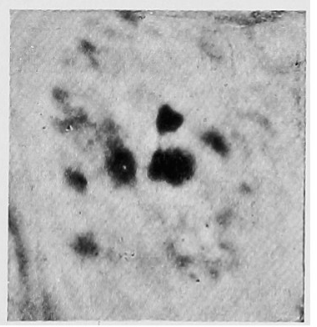

12

Catcheside: The chromosomes of a new haploid Oenothera 
Sax, K., 1930. Chromosome structure and the mechanism of crossing-over. J. Arnold Arboretum, 11 : 193-220.

Shull, G. H., 1921. Three new mutations in Oenothera Lamarckiana. J. Hered., 12: 354-63.

- 1927. Crossing-over in the third linkage group of Oenothera. Proc. Nat. Acad. Sci., 13: 21-4.

- 1928. A new gene mutation (mut. bullata) in Oenothera Lamarkiana and its linkage relations. Verh. V. int. Kongr. Vererb. (Zeits. f. ind. Abst.- u. Vererbungsl. Suppl. 2): 1322-42.

Stadler, L. J., 1931. The experimental modification of heredity in crop plants. I and II. Scientific Agriculture, 11: 557-72; 645-61.

Stomps, T. J., 1930a. UUber Parthenogenesis infolge Fremdbestäubung. Zeits. f. ind. Abst.- u. Vererbungsl., 54 : 243-5.

-1930b. Über Parthenogenetische Oenotheren. Ber. Deut. bot. Gesells., 48: 119-26.

Sturtevant, A. H., 1931. Genetic and cytological studies on Oenothera. I Nobska, Oakesiana, Ostreae, Shulliana, and the inheritance of old-gold flower-color. Zeits. f. ind. Abst.- u. Vererbungsl., 59: 365-80.

- and Dobzhansky, T., 1930. Reciprocal translocations in Drosophila and their bearing on Oenothera cytology and genetics. Proc. Nat. Acad. Sci., 16: 533-36.

Wenrich, D. H., 1916. The spermatogenesis of Phrynotettrix magnus, with special reference to synapsis and the individuality of the chromosomes. Bull. Mus. Comp. Zool. Harvar, 60, no. 3: 57-133.

de Vries, H., 1901-3. Die Mutationstheorie. Vols. I and II. Leipzig.

- 1917. Oenothera Lamarkiana mut. velutina. Bot. Gaz., 63: 1-24.

-1918a. Mass mutation and twin hybrids in Oenothera grandiflora Ait. Bot. Gaz., 65 : $377-422$.

-1918b. Mutations of Oenothera suaveolens Desf. Genetics, 3: 1-26.

-1918c. Twin hybrids of Oenothera Hookeri T. and G. Genetics, 3: 397-421.

- 1919. Oenothera Lamarckiana erythrina, eine neue Halbmutante. Zeits. f. ind. Abst. -u. Vererbungsl., 21 : 91-118.

- 1929. U̇ber das Auftreten von Mutanten aus Oenothera Lamarckiana. Zeits. f. ind. Abst. -u. Vererbungsl., 52: 121-90. 